OPEN ACCESS

Edited by:

Liwu Li,

Virginia Tech, United States

Reviewed by:

Maximiliano Gutierrez,

Francis Crick Institute,

United Kingdom

Isabelle Vergne,

Centre national de la recherche scientifique (CNRS), France

*Correspondence: Guillaume Tabouret g.tabouret@envt.fr

tThese authors have contributed equally to this work.

Specialty section:

This article was submitted to

Molecular Innate Immunity,

a section of the journal

Frontiers in Immunology

Received: 09 May 2017

Accepted: 21 August 2017 Published: 11 September 2017

Citation:

Walachowski S, Tabouret G, Fabre M and Foucras G (2017) Molecular

Analysis of a Short-term Model of $\beta$-Glucans-Trained Immunity Highlights the Accessory Contribution of GM-CSF in Priming Mouse Macrophages Response.

Front. Immunol. 8:1089. doi: 10.3389/fimmu.2017.01089

\section{Molecular Analysis of a Short-term Model of $\beta$-Glucans-Trained Immunity Highlights the Accessory Contribution of GM-CSF in Priming Mouse Macrophages Response}

\author{
Sarah Walachowskit, Guillaume Tabouret ${ }^{\star t}$, Marion Fabre and Gilles Foucras \\ Université de Toulouse, INRA, INP, ENVT, IHAP, Toulouse, France
}

$\beta$-Glucans (BGs) are glucose polymers present in the fungal cell wall (CW) and, as such, are recognized by innate immune cells as microbial-associated pattern through Dectin-1 receptor. Recent studies have highlighted the ability of the pathogenic yeast Candida albicans or its $\mathrm{CW}$-derived $\beta(1,3)(1,6)$-glucans to increase human monocytes cytokine secretion upon secondary stimulation, a phenomenon now referred as immune training. This ability of monocytes programming confers BGs an undeniable immunotherapeutic potential. Our objective was to determine whether BGs from Saccharomyces cerevisiae, a non-pathogenic yeast, are endowed with such a property. For this purpose, we have developed a short-term training model based on lipopolysaccharide re-stimulation of mouse bone marrow-derived macrophages primed with S. cerevisiae BGs. Through a transcriptome analysis, we demonstrated that BGs induced a specific gene expression signature involving the PI3K/AKT signaling pathway as in human monocytes. Moreover, we showed that over-expression of Csf2 (that encodes for GM-CSF) was a Dectin-1-dependent feature of BG-induced priming of macrophages. Further experiments confirmed that GM-CSF up-regulated Dectin-1 cell surface expression and amplified macrophages response along BG-mediated training. However, the blockade of GM-CSFR demonstrated that GM-CSF was not primarily required for BG-induced training of macrophages although it can substantially improve it. In addition, we found that mouse macrophages trained with BGs upregulated their expression of the four and a half LIM-only protein 2 (Fh/2) in a Dectin-1-dependent manner. Consistently, we observed that intracellular levels of FHL2 increased after stimulation of macrophages with BGs. In conclusion, our experiments provide new insights on GM-CSF contribution to the training of cells from the monocytic lineage and highlights FHL2 as a possible regulator of BG-associated signaling.

Keywords: $\beta$-glucans, macrophage, trained immunity, Dectin-1, GM-CSF

\footnotetext{
Abbreviations: BG, $\beta$-glucan; Curd, curdlan; CW, cell wall; DEG, differentially expressed genes; NEAA, non-essential amino acids; Pam3, Pam3CSK4; PAMP, pathogen-associated molecular pattern; Pen-Strep, penicillin-streptomycin; PRR, pattern recognition receptor; SEAP, secreted embryonic alkaline phosphatase; Sc, Saccharomyces cerevisiae; TEPM, thioglycollateelicited peritoneal macrophages; WGPd, dispersible whole glucan particle; WGPs, soluble whole glucan particle; WT, wild type; Zym, Zymosan.
} 


\section{INTRODUCTION}

The immune system has the complex task of detecting invading pathogens, a critical step in mounting efficient mechanisms of defense. For that, innate immunity has evolved an elaborated system of pathogen surveillance with a wide variety of receptors also referred as pathogen recognition receptors (PRRs) encompassing toll-like and C-type lectin receptors (TLRs and CLRs) $(1,2)$. These receptors are highly expressed by innate immune cells from the monocytic lineage and are able to recognize a broad spectrum of highly conserved micro-organisms-associated molecular patterns (MAMPs). The nature of MAMPs shapes the immune response orchestrated by macrophages and dendritic cells (3). Among CLRs, Dectin-1 is essential for mounting an effective innate immune response to fungal pathogens, as demonstrated in vivo by several authors using Clec $7 a$-deficient mice (4-6). The recognition of $\beta$-glucans (BGs) from the cell wall (CW) of various fungi, including yeasts, by Dectin-1 induces a Syk/CARD9 signaling cascade (7-11). Soluble BGs from Grifola frondosa have also been shown to stimulate the production of GM-CSF, a hematopoietic growth factor that could mediate part of their immunostimulant activity $(12,13)$. Indeed, in collaboration with Dectin-1 engagement, GM-CSF was shown to synergistically and robustly initiate a BG-specific inflammatory response in macrophages as well as in dendritic cells (12-15).

Moreover, it was demonstrated that TLR and Dectin-1associated signaling pathways could synergize to enhance macrophages response against pathogenic fungi as Candida albicans, Aspergillus fumigatus, and Pneumocystis carinii $(6,16-19)$. Indeed, the combination of TLR2/4 and Dectin-1dependent stimuli, such as those constituting yeasts $\mathrm{CW}$, including mannans, phospholipomannans, and BG, triggers a strong activation of macrophages secreting high levels of inflammatory cytokines (17, 20-22). However, we recently demonstrated that preferentially targeting Dectin-1 through BG enrichment from Saccharomyces cerevisiae $(S c)$ CW only elicit low or no relevant cytokine or chemokine production in mouse macrophages (23). And yet, several studies have brought pieces of major evidence that pre-exposure to C. albicans or C. albicans-derived BG could enhance the response of human monocytes to a secondary stimulation with TLR ligands, while respecting a 6-day resting period between pretreatment and re-stimulation $(24,25)$. This effect is now referred as BG-mediated immune training of monocytes $(26,27)$. Recent findings highlighted some molecular mechanisms involved in this long-term trained immunity model, including a metabolic shift toward aerobic glycolysis (a feature of cell activation and proliferation) via $\mathrm{PI} 3 \mathrm{~K} / \mathrm{AKT} / \mathrm{mTOR}$ pathway (28) and epigenetic modifications (29) in BG-trained human monocytes. Although GM-CSF priming was very recently shown to increase responsiveness to lipopolysaccharide (LPS) in a shortterm model of training (30), less is known regarding its role in BG-related trained immunity.

If producible to a large scale, $C$. albicans BG could be highly promising molecules to develop immunotherapeutic strategies where reprogramming of monocytes is required. Thus, we thought that $S c$ BG, presenting a quite analogous structure to those from C. albicans and industrially obtainable, could be used as surrogates, provided they share a similar ability to prime mononuclear phagocytes. In the perspective of deciphering the mechanisms underlying this effect and more convenient in vivo investigations, we attempted to establish a short-term model of trained immunity (devoid of resting period between both stimulations) with mouse macrophages.

By combining cellular and molecular approaches, we confirmed that pre-exposure of mouse macrophages with $S c$ BG promoted intense cytokine production upon secondary stimulation with TLR agonists. Through microarray analysis, we highlighted significant transcriptional modifications specific from $B G$ pretreatment. Among these, Csf2 and Fhl2 over-expression was further investigated to evaluate their potential contribution to BG-induced priming of mouse macrophages.

\section{MATERIALS AND METHODS}

\section{Reagents}

Cell culture media RPMI 1640 GlutaMAX $^{\mathrm{TM}}$ and DMEM GlutaMAX $^{\mathrm{TM}}$, PBS, non-essential amino acids (NEAA), sodium pyruvate and antibiotics [Penicillin-Streptomycin (Pen-Strep ${ }^{\mathrm{TM}}$ ), Gentamicin $^{\mathrm{TM}}$, Normocin ${ }^{\mathrm{TM}}$, and Zeocin ${ }^{\mathrm{TM}}$ ] were purchased from GIBCO (Life Technologies). Fetal bovine serum (FBS) was provided by Eurobio, France. Zymosan (Zym), particulate and dispersible whole glucan particle (WGPd, Biothera) and soluble whole glucan particle compounds (WGPs, Biothera) and curdlan (Curd), a linear $\beta 1,3$-glucan extracted from Alcaligenes faecalis, synthetic triacylated lipoprotein Pam3CSK4 (Pam3) and ultraPure LPS from Escherichia coli O111:B4 were purchased from InvivoGen (France). BG compounds of interest were extracted from the same strain of S. cerevisiae owned by PhileoLesaffre Animal Care. Their composition was already described in a recent study (23). The previous name given to the crude compounds BG15 was replaced in this study by ScCW for better understanding and more convenience.

\section{Animals}

Wild type (WT) C57Bl/6 mice were purchased from Janvier Labs (St Berthevin, France) and $\mathrm{Clec}^{-a^{--}}$mice (5) were originally provided by Pr. Gordon Brown (University of Aberdeen, Scotland) and were bred in-house. Eight- to 12 -week-old C57Bl/6 Clec $7 \mathrm{a}^{-/-}$ mice and their strain-matched WT controls from both sexes were housed under pathogen-free conditions in an accredited research animal facility of the National Veterinary College (UMR IHAP, Toulouse, France). This study was carried out in strict accordance with the Federation of European Laboratory Animal Science Association guidelines (FELASA). Experiments were performed by FELASA accredited investigators (no. 311155580) and approved by the local ethics committee, "Science et Santé Animale" (SSA). All efforts were made to minimize animal pain and distress.

\section{Cells and Bacteria}

\section{NFкB/AP-1 Activity Using Reporter Cell Line}

The NFkB/AP-1 reporter RAW-Blue ${ }^{\mathrm{TM}}$ Cells (InvivoGen ${ }^{\mathrm{TM}}$ ) were cultured and propagated according to the manufacturer's recommendations. The NFkB/AP-1 activity was assessed as described 
in Walachowski et al. (23). RAW-Blue ${ }^{\mathrm{TM}}$ macrophages $\left(1 \times 10^{5}\right.$ cells/well) were stimulated with $100 \mu \mathrm{g} / \mathrm{mL}$ of BG-containing preparations (ScCW, BG65, and BG75) for $8 \mathrm{~h}$. Supernatants were then removed and $100 \mathrm{ng} / \mathrm{mL}$ of ultraPure LPS was added in each well for the rest of the stimulation period. Supernatants were collected and stored at $-20^{\circ} \mathrm{C}$ or processed immediately. Secreted embryonic alkaline phosphatase was measured using a colorimetric enzymatic assay. Supernatants were incubated with Quanti-Blue ${ }^{\mathrm{TM}}$ (InvivoGen) $25 \% \mathrm{v} / \mathrm{v}$. for $2 \mathrm{~h}$ at $37^{\circ} \mathrm{C}$, and optical density (OD $650 \mathrm{~nm}$ ) was measured (VERSAmax plate reader, Molecular Devices).

\section{Bacteria}

Staphylococcus aureus $\mathrm{N} 305$ and E. coli $\mathrm{P} 4$ strains were prepared as described previously by Accarias et al. (31) using growth medium adapted to each strain of bacteria [tryptic soy broth for N305 and Lysogeny broth (LB) for P4]. Briefly, a 100-fold dilution of the overnight bacteria culture was grown in medium to mid log phase to obtain an OD600 $\mathrm{nm}$ of around 1. After cautious washing and homogenization, the concentration of bacteria was estimated by measuring the absorbance at $600 \mathrm{~nm}$ (considering that 1 D.O. unit corresponds to $5 \times 10^{8} \mathrm{CFU} / \mathrm{mL}$ ) and was adjusted to the desired concentration. CFUs were further determined in serially diluted inoculum after $24 \mathrm{~h}$ of culture on agar plates.

\section{Primary Cell Culture and Functional Assays}

Murine wild type or $C l e c 7 a^{-1-}$ bone marrow-derived macrophages (BMDM) were obtained as described previously (31). Inflammatory peritoneal macrophages were elicited and handled as previously described (23). BMDM and thioglycollate-elicited peritoneal macrophages $($ TEPM $)\left(1 \times 10^{5}\right.$ cells/well) were seeded in 96-well tissue culture plates for $16 \mathrm{~h}$ in complete RPMI until complete adherence $\left(37^{\circ} \mathrm{C}, 5 \% \mathrm{CO}_{2}\right)$. Non-adherent contaminating peritoneal cells were eliminated by repeating three gentle washings of wells with pre-warmed culture medium or PBS. After stimulation with Sc BG compounds or Dectin-1 ligands controls (WGPd, WGPs or Zym) for $8 \mathrm{~h}$, supernatants were removed and cells were then stimulated with $100 \mathrm{ng} / \mathrm{mL}$ of ultraPure LPS or Pam3, or with live bacteria (S. aureus N305 or E. coli P4 strains, MOI $=10$ ) for $1 \mathrm{~h}$ followed by $16 \mathrm{~h}$ incubation with cell culture medium supplemented with Gentamicin ${ }^{\mathrm{TM}}$. Supernatants were then collected, complete protease inhibitor cocktail (Roche, France) was added in infected conditions, and supernatants were finally stored at $-20^{\circ} \mathrm{C}$ or $-80^{\circ} \mathrm{C}$ until further use.

For the dose-dependent experiments, BMDM were preincubated with 1:10 serial dilution of BG75 from 0.1 to $100 \mu \mathrm{g} /$ $\mathrm{mL}$ before another $16 \mathrm{~h}$ LPS stimulation. For the two kinds of kinetics assays, several time points were used for BG incubation $(1,4,8$, or $16 \mathrm{~h}$ ) before $16 \mathrm{~h}$ of LPS stimulation as well as for LPS stimulation $(1,4,8$, or $16 \mathrm{~h})$ after $8 \mathrm{~h}$ of BG incubation.

For short-term model of immune training, cells were pretreated with BG75 or complete RPMI as above. After the first incubation, BMDM were washed with warm PBS and maintained in complete RPMI for 24 or $72 \mathrm{~h}$. Thereafter, cells were submitted to a secondary stimulus using $100 \mathrm{ng} / \mathrm{mL}$ of ultraPure LPS for $16 \mathrm{~h}$. For GM-CSF and M-CSF influence analyses, BMDM were first pre-incubated for $2 \mathrm{~h}$ with recombinant GM-CSF (rGM-CSF, 5 ng/mL, PeproTech, Rocky Hill, NJ, USA) or M-CSF (rM-CSF, $5 \mathrm{ng} / \mathrm{mL}$, PeproTech, Rocky Hill, NJ, USA), or using serial 10-fold dilutions as described in corresponding figure legends. Cells were then stimulated with 100 or $10 \mu \mathrm{g} / \mathrm{mL}$ of BG75 for $8 \mathrm{~h}$ followed, where applicable, by 16-h LPS stimulation.

For blocking antibody assays, macrophages were pre-incubated with blocking anti-GM-CSFR antibodies or their isotype control (Novus Biologicals, CO, USA) for $1 \mathrm{~h}$, followed by incubation with rGM-CSF $(100 \mathrm{pg} / \mathrm{mL})$ for $2 \mathrm{~h}$. Then BMDM were treated with BG75 $(100 \mu \mathrm{g} / \mathrm{mL})$ for $8 \mathrm{~h}$ and further stimulated with $100 \mathrm{ng} /$ $\mathrm{mL}$ of LPS for $16 \mathrm{~h}$. All triplicate supernatants were harvested and handled as previously described before cytokine measurement.

\section{Quantification of Cytokines and Chemokines by ELISA}

TNF $\alpha$, IL-6, and IL-1 $\beta$ (Biolegend, Ozyme-France) and GM-CSF (R\&D Systems, France) levels in culture supernatants were assayed using individual cytokine detection kits according to the manufacturer's recommendations. Data are expressed as the mean \pm SD and are representative of three individual experiments performed in triplicate.

\section{Dectin-1 and CD11b Surface Expression Analysis by Flow Cytometry}

Wild-type BMDM were incubated with rGM-CSF $(5 \mathrm{ng} / \mathrm{mL})$ or $\mathrm{rM}$-CSF $(5 \mathrm{ng} / \mathrm{mL})$ or medium for $2 \mathrm{~h}$. Supernatants were discarded and cells were collected using cold PBS supplemented with $5 \mathrm{mM}$ EDTA. After harvest, cells were centrifuged (300 g, $5 \mathrm{~min}$ ) and absolute macrophages number was determined by flow cytometry (MACSQuant, Miltenyi Biotech, Germany). BMDM were pre-incubated with anti-CD16/CD32 (Biolegend, OzymeFrance) to block Fc $\gamma$ RII/III receptors and then incubated with the following fluorochrome-conjugated mAbs: anti-Dectin-1 (2A11; $\mathrm{AbD}$ serotec) or its isotype control IgG1 (A110-1, BD biosciences Pharmingen) and anti-CD11b (M1/70, Biolegend) or its isotype control. A 7-AAD staining (Biolegend, Ozyme-France) was used to discriminate death cells and doublets of cells were excluded with a gating on FSC-H/FSC-A. The acquisition was performed on $1 \times 10^{5}$ cells using MACSQuantify software (Miltenyi Biotech, Germany). Data were analyzed with FlowJo software (FlowJo LLC, USA).

\section{Microarray Analysis}

After stimulation with $S c$ BG compounds and then with ultraPure LPS, BMDM were lysed in Buffer RLT (Qiagen, Hilden, Germany) and was subjected to RNA extraction using the RNeasy Mini Kit (Qiagen, Hilden, Germany) according to the manufacturer's instructions. RNA was quantified with a NanoDrop ${ }^{\circledR} 1000$ spectrophotometer and NanoDrop 1000.3.7 software.

RNA quality assessment and microarray experiment were performed at the GeT-TRiX platform (INRA, Toulouse, France). RNA quality was assessed using the Agilent RNA 6000 Nano Kit on BioAnalyzer and 2100 Expert Software (Agilent Technologies, Santa Clara, CA, USA). RNA samples with RNA integrity number more than 8.5 were chosen to be prepped for further analysis. A 
total RNA material of 100 ng was amplified and labeled using a Low Input QuickAmp Labeling kit (Agilent Technologies, Santa Clara, CA, USA). RNA were hybridized to Agilent Sure Print G3 Mouse GE $8 \times 60 \mathrm{~K}$ microarrays, washed, stained, and scanned on an Agilent G2505C instrument following the manufacturers' protocols. Agilent Feature Extraction software was used to analyze signal intensity values of the spots generated from the scans. Posthybridization quality controls were done to eliminate outliers and irrelevant data from the expression data set. Background was subtracted and data were normalized using Agilent procedure. All validated and normalized transcripts expression data were processed using the Agilent GeneSpring GX software.

All entities with flag values present in at least 1 out of the eight conditions were considered. Statistical analysis (two-way ANOVA) was used to generate a unique list of up- or downregulated entities with associated Benjamini-Hochberg false discovery rate corrected $p$-value and fold change (FC) and for hierarchical clustering. Transcripts with detection $p$-value of less than or equal to 0.001 in at least one sample were selected for further analysis. A filter was set to include only transcripts that had at least 1.5-FC compared to the LPS-stimulated cells without BG treatment control.

Using Ingenuity Pathway Analysis (IPA) software, a final list of unique identified genes ( $p$-value $<0.001$ and absolute FC $\geq 2$ ) was generated after selection of mapped entities and deduplication exercise on them, and which was then used to perform IPA biofunction analysis. IPA categorized modulated genes according to $p$-values (calculated by the Fisher exact test) and $z$-scores. The $z$-score predicts the direction of change of a function: a function is increased when $z$-score is $\geq 2$ and decreased when $z$-score $\leq 2$. IPA also calculated a bias-corrected $z$-score to correct dataset bias (i.e., when there are more up- than downregulated genes in a bio-function or vice-versa). Lists of modulated genes $(\mathrm{FC} \geq 1.5)$ were also processed using InnateDB online tool to identify the biological functions associated with the primary BG compounds treatment ( $p$-value $<0.001$ ). All data files have been deposited in NCBI's Gene Expression Omnibus and are accessible through GEO series accession number GSE101959 (https://www.ncbi. nlm.nih.gov/geo/query/acc.cgi?acc=GSE101959).

\section{Gene Expression by Quantitative Polymerase Chain Reaction Analysis}

Total RNA (300 ng) was reverse transcribed using the SuperScript III First-Strand Synthesis Super Mix Kit (Invitrogen) as per the manufacturer's protocol. Quantitative PCR was performed individually with Power SYBR Green PCR Master Mix (Applied Biosystems) and LightCycler ${ }^{\mathrm{TM}} 480$ (Roche, France) for Csf2 and Fhl2; or with the Biomark HD System (Fluidigm, France) at the GeT-PlaGe genotyping service platform (INRA, Toulouse, France) according to the manufacturer's recommendations. For individual quantification, dissociation curves analysis was performed at 40 cycles to verify the identity of PCR product. Primer3plus software was used to design the primers (Table S1 in Supplementary Material) and housekeeping genes were selected with GeNorm Software. The abundance of mRNA of interest was normalized to that of Sdha, Rpl9, and Hprt1 and relative expression was calculated using the $2^{-\Delta \Delta \mathrm{Ct}}$ method. The comparative threshold cycle values are expressed as arbitrary unit.

\section{Western Blot}

After $8 \mathrm{~h}$ of $S c \mathrm{CW}$ extracts stimulation, WT BMDM were exposed to $100 \mathrm{ng} / \mathrm{mL}$ of ultraPure LPS for $16 \mathrm{~h}$. Supernatants were removed and cells were then lysed in RIPA lysis buffer supplemented with $5 \mathrm{mM}$ EDTA and protease inhibitor (Pierce ${ }^{\mathrm{TM}}$, USA). Lysates were centrifuged (14000 rpm, $10 \mathrm{~min}$ ), pellets were discarded and proteins concentrations were determined using BCA kit (Pierce ${ }^{\mathrm{TM}}$, USA). Following a 1:1 dilution in Laemmli buffer (Biorad, CA, USA), $10 \mu \mathrm{g}$ of total protein were separated on NuPAGE ${ }^{\circledR} 4-12 \%$ Bis-Tris Mini gels (1.0 mm, 12 wells, Invitrogen ${ }^{\mathrm{TM}}$ ) and blotted onto nitrocellulose membrane $\left(0.2 \mu \mathrm{m}\right.$, Invitrogen $\left.{ }^{\mathrm{TM}}\right)$ using the XCell SureLock ${ }^{\mathrm{TM}}$ Mini gel system (Invitrogen ${ }^{\mathrm{TM}}$, USA). After blocking with 1\% BSA and $0.05 \%$ Tween 20 (Sigma-Aldrich ${ }^{\circledR}$, USA) in Tris-Buffer Saline (TBS, Euromedex, France), the membrane was stained with primary anti-FHL2 (F4B2-B11) and anti- $\beta$-actin (C4) as loading control mAbs (Santa Cruz Biotechnologies, Germany) at $4^{\circ} \mathrm{C}$, overnight. The membrane was then washed in TBS with $0.05 \%$ Tween 20 and incubated with goat anti-mouse antibodies conjugated with horseradish peroxidase (Jackson ImmunoResearch, PA, USA) for $1 \mathrm{~h}$ at room temperature. Signals were detected with Clarity ${ }^{\mathrm{TM}}$ Western ECL substrate and the ChemiDoc ${ }^{\mathrm{TM}} \mathrm{MP}$ instrument according to the manufacturer's instructions (Biorad, CA, USA). Image Lab software was used for minor linear adjustments in contrast, if needed and the quantitative tool was used to determine the relative quantity of FHL2 protein in each sample as compared to the reference value (fixed to 1) corresponding to the untouched macrophages condition.

\section{Statistical Analysis}

All experiments were performed three times unless otherwise specified and data are expressed as the mean \pm SD of the values from all experiments. Each condition was performed in triplicate. Statistical significance was assessed using a two-tailed unpaired Student's $t$-test or a two-way ANOVA analysis (as stated in the figure legends) with a threshold set at $p<0.05$. Mean values shown with different letters on plots are significantly different. For these analyses, we used XLStat (Addinsoft, France) and GraphPad Prism 5 (San Diego, CA, USA) softwares.

\section{RESULTS}

\section{Priming with S. cerevisiae BGs Enhances the Macrophage Response to Secondary Stimulation with TLR Ligands in a Dectin- 1-Dependent Manner}

In vitro, pre-incubation of TEPM with various yeast $\mathrm{CW}$-derived products resulted in different degrees of cytokine production. As previously published (23), unpurified or poorly purified products such as Zym or crude CW induced strong cytokine secretion as measured in the culture supernatants (Figure 1A). In comparison, the secretion induced by particulate BG-enriched products was lower but still significant if compared to mock or soluble BG 

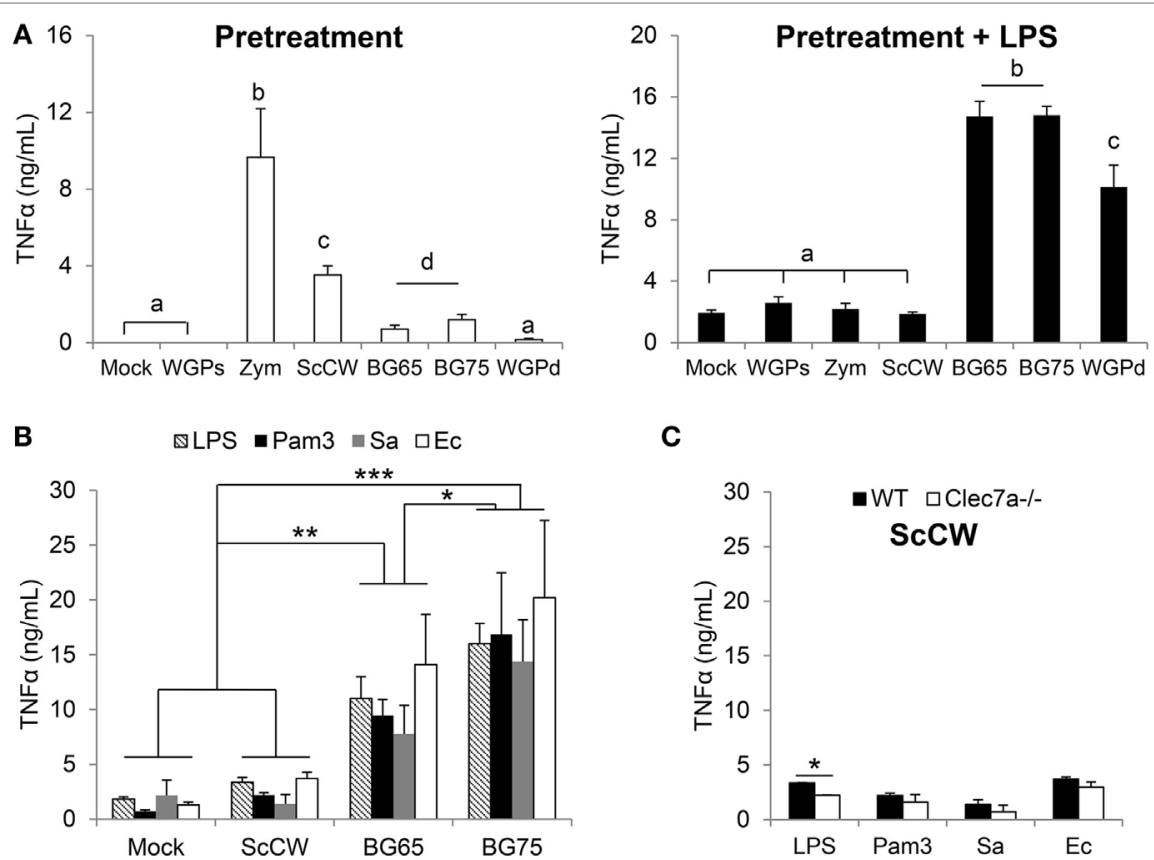

C
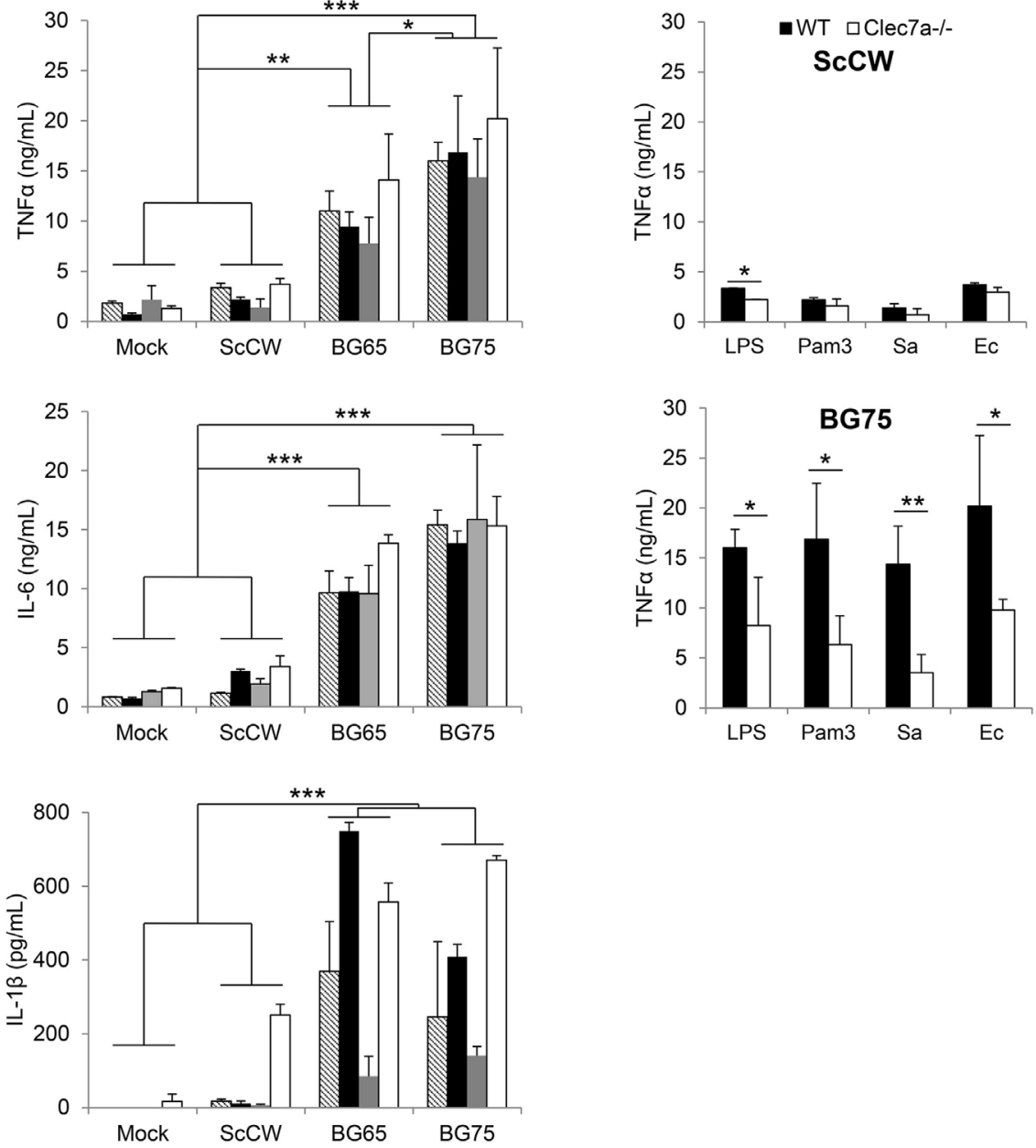

FIGURE 1 | BG-enriched preparations of Saccharomyces cerevisiae cell wall (ScCW) prime the macrophage response predominantly via Dectin-1 upon toll-like lectin receptor (TLR) ligands or whole bacteria exposure. Wild-type (WT) thioglycollate-elicited peritoneal macrophages (A) and WT or Clec7a-/- bone marrowderived macrophages from C57BL/6 mice (B,C) were stimulated with $100 \mu \mathrm{g} / \mathrm{mL}$ of crude (ScCW) or BG-enriched (BG65, BG75) compounds for 8 h. After incubation, cell culture supernatants were collected [panel (A) on the left, white bars] and stored at $-20^{\circ} \mathrm{C}$. Cells were then stimulated with $100 \mathrm{ng} / \mathrm{mL}$ of ultraPure lipopolysaccharide (LPS) for $16 \mathrm{~h}$ [panel (A) on the right: dark bars, (B) and (C)] or Pam3CSK4 (Pam3) [(B) and (C)]. For the stimulation with live bacteria, Staphylococcus aureus N305 or Escherichia coli P4 strains were used at MOI $=10$ for $1 \mathrm{~h}$, followed by $16 \mathrm{~h}$ incubation with cell culture medium supplemented with Gentamicin $^{\mathrm{TM}} \mathbf{( B )}$ and $\mathbf{( C )}$. At the end of the incubation, supernatants were collected and immediately stored at $-20^{\circ} \mathrm{C}$. TNF $\alpha$, IL-6, and IL $1 \beta$ were quantified by ELISA. Data are expressed as the mean \pm SD from three independent experiments performed in triplicate. In (A,C), a Student's $t$-test was used to assess significance between conditions ( $\left.{ }^{*} p<0.05 ;{ }^{* *} p<0.01\right)$ and mean values not sharing the same letter in (A) are significantly different. In (B), a two-way ANOVA with Bonferroni post-tests was used to compare pretreatment conditions $\left({ }^{\star} p<0.05 ;{ }^{* *} p<0.01,{ }^{* \star *} p<0.001\right)$.

(WGPs) which seemed devoid of activity. The results appeared strikingly different when pre-incubated macrophages were further stimulated with LPS. Indeed, pre-treating TEPM with BG
(BG65, BG75, and WGPd) enhanced their response to LPS by at least a factor of 10 compared to untreated cells or cells pretreated with WGPs. Surprisingly, ScCW or Zym preparations, despite 
the presence of low concentrations of BG, did not amplify TEPM response to LPS. We next confirmed these observations by using BMDM pre-incubated with crude $\mathrm{CW}$ (ScCW) or purified BG (BG65/BG75) and further stimulated with various TLR agonists (Figure 1B). As with TEPM, pretreating BMDM with BG dramatically enhanced their response to TLR agonists whether these were presented to macrophages as purified molecules (TLR4: LPS, TLR2: Pam3) or in the context of living Gram-positive or Gram-negative bacteria ( $S$. aureus and E. Coli, respectively). This effect was observed for the three inflammatory cytokines TNF $\alpha$, IL-6, or IL-1 $\beta$, and again, pretreatment with ScCW (or Zym, data not shown) did not allow significant priming of the macrophage response. Given significant levels of IL-1 $\beta$ measured in BG-enriched pretreatment conditions, we evaluated the viability of BMDM using Propidium Iodide labeling assay. Any difference of fluorescence between mock and BG75-pretreated experimental conditions was detected before or after LPS stimulation, meaning that cells were perfectly viable in our short-term training model (Figure S1 in Supplementary Material).

Bone marrow-derived macrophages from $\mathrm{Clec} \mathrm{a}^{-/-}$mice, which do not express Dectin-1, the main surface receptor of BG, were then used to evaluate the influence of the Dectin-1 pathway in the ability of BG to prime macrophages. Whereas the absence of Dectin-1 had no effect on the ScCW-mediated response, it significantly inhibited the ability of BG to prime BMDM response against TLR agonists (Figure 1C). Nevertheless, this inhibition was only partial and led to a reduction by $60 \%$ on average of cytokine production. Moreover, the surface expression of TLR4 on BMDM was evaluated after BG pretreatment, and we showed that the BG-induced exacerbated cytokine response observed following a secondary LPS stimulation is not explained by an upregulation of TLR4 levels at the surface of BMDM (Figure S2 in Supplementary Material). Of interest, priming of macrophages was perfectly correlated with the dose of BG used during pretreatment (Figure 2A). We determined that $1 \mu \mathrm{g} / \mathrm{mL}$ was enough to prime macrophages although concentrations higher than $10 \mu \mathrm{g} /$ $\mathrm{mL}$ were significantly more efficient. Next, we evaluated the incubation time needed for BG to exert their priming effect on the macrophage response to secondary stimuli. First, the simultaneous addition of BG or ScCW and LPS (co-stimulation) or short pre-incubation times (up to $4 \mathrm{~h}$ ) only resulted in a slight increase of the macrophage response reflecting the previously described synergism between TLR and Dectin-1 pathways $(6,17,19)$. By contrast, longer pre-incubation times allowed a significant priming of macrophages but exclusively when using BG-enriched preparations (Figure 2B). In parallel, we also assessed importance of the time for the secondary stimulation to maximize cytokine production. By doing so, we observed that, as expected, TNF $\alpha$ levels produced in response to LPS stimulation rose with the incubation time (Figure 2C). However, for shorter LPS incubation times (from 1 up to $8 \mathrm{~h}$ ), no difference was noticed between TNF $\alpha$ levels produced by untreated or BG-pretreated macrophages. Thus, at least $16 \mathrm{~h}$ of incubation with LPS were needed to observe significant differences between pretreatment conditions. A good correlation was identified between $\mathrm{NF \kappa B}$ / AP-1 activity and incubation times after LPS stimulation. However, after $16 \mathrm{~h}$ of incubation, the levels of TNF $\alpha$ secretion and NFkB/AP-1 activity did not match (Figure 2D), suggesting that the increased secretion of cytokine induced by BG pretreatment did not rely on NFKB/AP-1 activity. Finally, we evaluated how long the priming effect of BG on macrophages lasted. As shown in Figure 2E, enhancement of the macrophages response to LPS could be observed at least up to $72 \mathrm{~h}$ after BG pretreatment. This was also observed for longer latency times and up to 5 days (data not shown). Taken together, these results indicate that BG priming is a slow process that probably involves de novo protein synthesis and induces profound and long-lasting changes in macrophage biology and phenotype.

\section{Transcriptome Analysis Reveals Specific Hallmarks of BG-Primed Macrophages}

To get further insight on how BG altered macrophages responsiveness, we performed a gene expression analysis by microarray. Gene expression profiling was performed in BMDM pretreated with ScCW, BG65, and BG75, or mock controls for $8 \mathrm{~h}$, and then stimulated with LPS for 4 and $8 \mathrm{~h}$. Using a two-way ANOVA with a false discovery rate of 0.001 and a fold expression difference of at least 1.5 , we determined differentially expressed genes (DEG) between conditions of priming: BG65, BG75, or ScCW versus mock (Figure 3A). A total of 787/670 (4 h) and 935/664 (8 h) DEG were found when comparing BG65/BG75 versus mock. Comparatively, $\mathrm{ScCW}$ pretreatment modified the expression of a greater number of genes (2,268 and 1,627 at 4 and $8 \mathrm{~h}$, respectively). Microarray results were confirmed using RT-qPCR on a different set of samples. qPCR results were strongly correlated with the microarray results for all the genes that were evaluated ( $n=26$ genes), with a Pearson's correlation coefficient of 0.57 ( $p$-value $<0.001$ ), and confirmed most of the microarray results (Figure S3A in Supplementary Material).

Based on a fold difference above 5, DEG were organized by hierarchical clustering (Euclidian distance) according to similarities in the expression profiles. Conditions with BG65 and BG75 clustered together in contrast to ScCW and mock conditions that remained separated, and so whatever the time point analyzed (Figure 3B). The discrimination was also confirmed by principal component analysis (data not shown). Two gene clusters (1 and 3 ) were associated with pretreatment of macrophages with BG. Cluster 1 was composed of only three differentially up-regulated genes by BG65/75: Csf2, Fhl2, and Cish that presented the highest FC compared to mock (Table 1, A). Interestingly, these genes were poorly modulated in ScCW pretreatment condition. Consequently, genes from cluster 1 could be considered as hallmarks of BG-enriched pretreatment of macrophages. Cluster 3 was also associated with BG pretreatment and comprised 40 DEG. However, these genes were also modified in ScCW condition but with a lower FC compared to BG pretreatment. The comparison between BG75 and ScCW pretreatments confirmed that, although ScCW contains very limited BG (15\%), stimulation with BG-enriched preparations triggered specific pathways in macrophages (Table 1, B). Clusters 2 and 4 comprised genes specifically modulated by ScCW pretreatment. Cluster 2 comprised 35 genes that were downregulated in $\mathrm{ScCW}$ condition but precociously (after $4 \mathrm{~h}$ of LPS stimulation) over-expressed in mock and BG conditions. Cluster 4 comprised 47 genes 

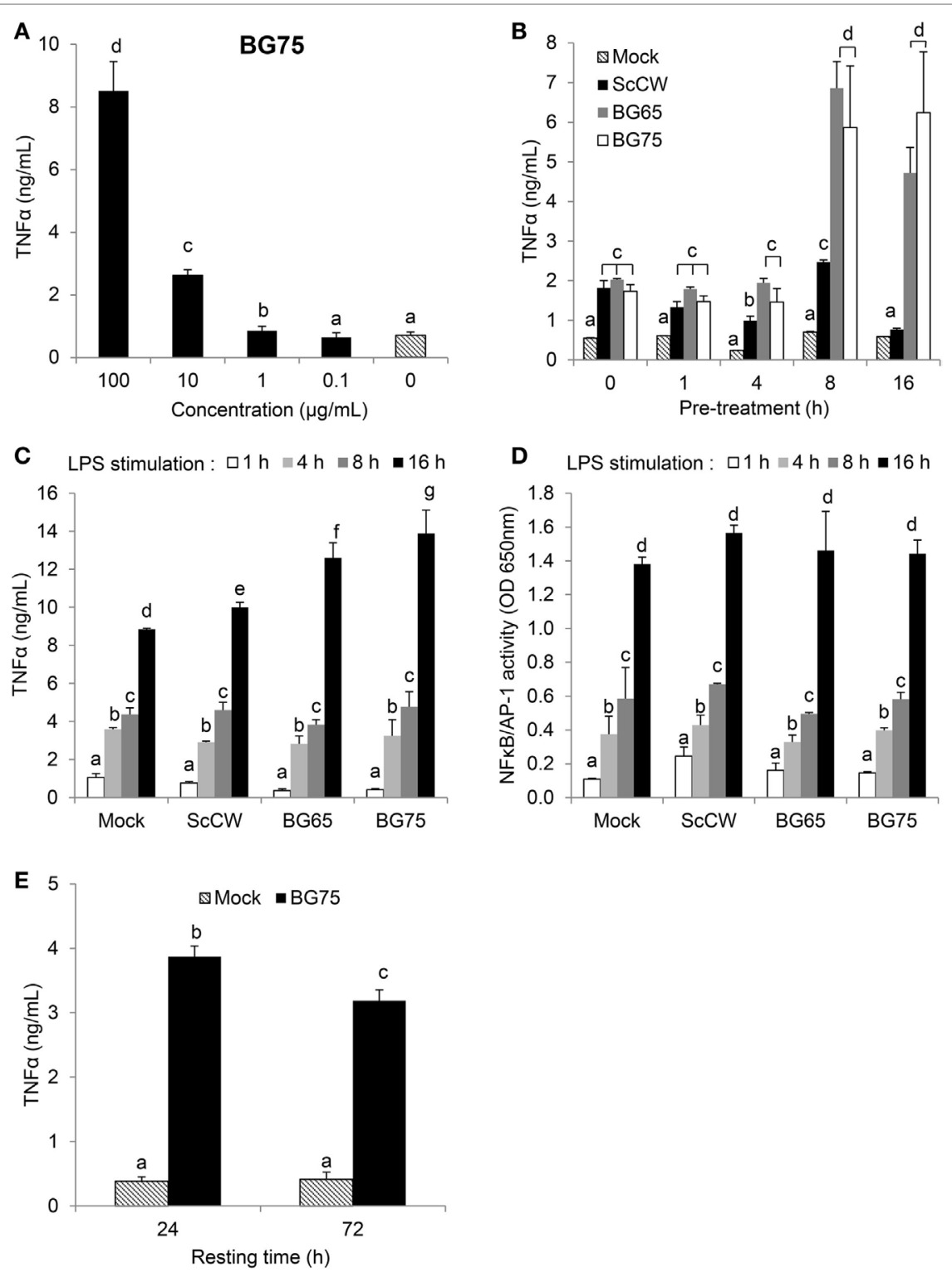

FIGURE 2 | $\beta$-glucans (BGs) prime the production of TNF $\alpha$ in macrophages via a late and dose-dependent mechanism lasting beyond BG incubation. (A,B,E) bone marrow-derived macrophages (BMDM) were subcultured in 96-well plates. (A) Cells were incubated for $8 \mathrm{~h}$ with a 10 -fold serial dilution from 100 to $0.1 \mu \mathrm{g} / \mathrm{mL}$ of BG75. After supernatant removal, BMDM were then stimulated with $100 \mathrm{ng} / \mathrm{mL}$ of ultraPure lipopolysaccharide (LPS) for $16 \mathrm{~h}$. Supernatants were collected at the end of the incubation for further analysis. (B) Cells were stimulated for 1, 4, 8, 16, and $24 \mathrm{~h}$ with $100 \mu \mathrm{g} / \mathrm{mL}$ of BG-containing products (ScCW, BG65, and BG75). Supernatants were discarded and $100 \mathrm{ng} / \mathrm{mL}$ of ultraPure LPS was added in each well for $16 \mathrm{~h}$ incubation. Supernatants were immediately collected and stored at $-20^{\circ} \mathrm{C}$. TNF $\alpha$ was measured using ELISA and data are expressed as the mean \pm SD from two independent experiments performed in triplicate. (C,D) NFKB/AP-1 reporter RAW-Blue ${ }^{\mathrm{TM}}$ macrophages were treated with $100 \mu \mathrm{g} / \mathrm{mL}$ of BG-containing compounds for $8 \mathrm{~h}$ before stimulation with $100 \mathrm{ng} / \mathrm{mL}$ of ultraPure LPS for 1 , 4 , 8 , or $16 \mathrm{~h}$. At the end of the incubation, supernatants were harvested and stored at $-20^{\circ} \mathrm{C}$ until further use. NFKB/AP-1 activity was determined by a colorimetric enzyme assay where cell culture supernatants were incubated with Quanti-Blue ${ }^{\mathrm{TM}}$ reagent before reading OD at 650 nm. TNF $\alpha$ was quantified by ELISA. Data are expressed as the mean \pm SD from three independent experiments performed in triplicate. (E) BMDM were incubated for $8 \mathrm{~h}$ with $100 \mathrm{\mu g} / \mathrm{mL}$ of BG75 or control. After supernatant removal, fresh medium was added for further 24 or $72 \mathrm{~h}$ (resting time) and cells were stimulated with $100 \mathrm{ng} / \mathrm{mL}$ of ultraPure LPS for $16 \mathrm{~h}$. Supernatants were collected and stored at $-20^{\circ} \mathrm{C}$. TNF $\alpha$ was measured using ELISA and data are expressed as the mean \pm SD from three independent experiments performed in triplicate. Mean values not sharing the same letter are significantly different according to the Student's $t$-test $(p<0.05)$. For (B-D), results of statistical analyses are displayed for comparisons between each compound according to the incubation time.

significantly upregulated after $8 \mathrm{~h}$ of LPS exposure (and to a lesser extent at $4 \mathrm{~h}$ ) but exclusively in ScCW-pretreated macrophages. By contrast, these genes were down-modulated in mock or BG pretreatment conditions (Table S2 in Supplementary Material).
These results demonstrate that pretreatment of macrophages with BG-enriched preparations induced the modulation of a specific array of genes that were distinct from those modulated by ScCW pretreatment. 

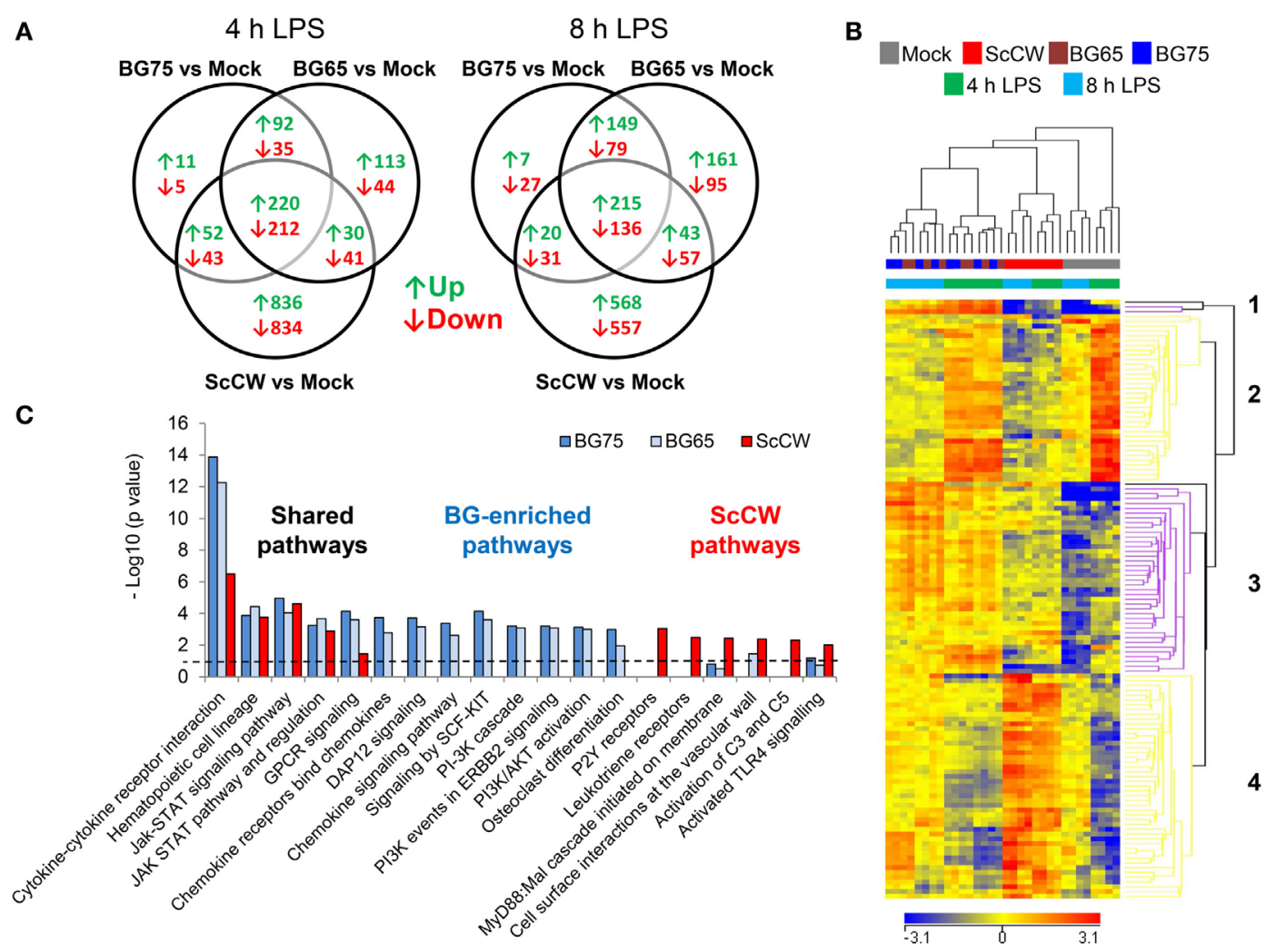

FIGURE 3 | Gene expression profiling reveals specific hallmarks of $\beta$-glucan (BG)-pretreated macrophages after lipopolysaccharide (LPS) exposure. Wild-type bone marrow-derived macrophages (BMDM) were cultured in 24-well plates and treated with $100 \mu \mathrm{g} / \mathrm{mL}$ of the set of three BG extracts for $8 \mathrm{~h}$ in triplicate. After incubation, supernatants were removed and cells were stimulated with $100 \mathrm{ng} / \mathrm{mL}$ of ultraPure LPS for $4 \mathrm{or} 8 \mathrm{~h}$. A microarray analysis was performed using Agilent mRNA transcriptomic analysis. After quality control and normalization, data were analyzed using Agilent GeneSpring GX software by two-way ANOVA and Benjamini-Hochberg post hoc correction. Transcripts with a $p$-value of less than or equal to 0.001 and a fold change (FC) value of at least 1.5 between conditions in at least one sample were selected for further analysis. (A) Venn diagrams showing the overlap of upregulated ( $\uparrow$ ) and downregulated ( $\downarrow$ ) genes in each condition were obtained using VENNY 2.0. (B) Unsupervised hierarchical clustering (Euclidian distance) of transcriptional profiles, displayed as a heatmap of FC expression values, from BG-treated BMDM compared to non-treated BMDM upon LPS exposure. Each row represents a transcript and each column an individual sample. The heatmap shows 4 clusters constituted by entities with a $p$-value of 0.001 for which FC were greater than 5 compared to mock plus $8 \mathrm{~h}$ LPS-stimulated cells. Red indicates over-expressed and blue indicated under-expressed transcripts. (C) Based on a comparison of FC expression values between BG pretreatments and the non-pretreated condition upon $8 \mathrm{~h}$ of LPS exposure obtained from GeneSpring software ( $F C>1.5$ ), we performed a pathway over-representation analysis using Innate DB. Significant pathways which $p$-values (calculated by the hypergeometric algorithm) were lower than 0.05 are displayed for each BG pretreatment condition (threshold value-log $p$-value $=1.30$ ).

Based on these panels of DEG, we performed a functional analysis using InnateDB online tool to uncover macrophage pathways that were significantly influenced by each pretreatment. Among the pathways identified (with a corrected $p$-value $<0.05$ ), some were clearly specific to each pretreatment whereas some were shared (Figure 3C; Figure S3B in Supplementary Material). JAK-STAT signaling and regulation and hematopoietic cell lineage pathways were targeted by BG and ScCW pretreatments in a similar extent. By contrast, although commonly targeted, cytokine-cytokine receptor interactions and G-protein-coupled receptors (GPCRs) signaling (strongly associated with Csf2 overexpression) appeared much more induced by BG65/75 pretreatments and this was compatible with the enhanced cytokine response observed (Figure 1). Compared to BG-enriched conditions, ScCW showed a significant enrichment for TLR signaling pathways associated with MyD88 cascade, complement activation, and also functions linked to leukotriene and P2Y (Purinergic GPCRs) receptors (GPCRs signaling). This result confirmed that $\mathrm{ScCW}$ pretreatment significantly stimulated TLR cascade in macrophages (Figure 1A). By contrast, we identified functions specifically triggered by BG pretreatment mainly related to $\mathrm{PI} 3 \mathrm{~K} / \mathrm{AKT}$ pathway (cascade, activation, and events in ERBB2, SCF-KIT, and DAP12 signaling). In line with this result, we observed a significant increase of $\mathrm{NAD}^{+} / \mathrm{NADH}$ ratio in macrophages following BG75 exposure, a biological feature linked to aerobic glycolysis (Warburg effect) and activation of cell metabolism through PI3K/AKT signaling (Figure S4 in Supplementary Material). Moreover, several genes coding for chemokines and chemokines receptors (Cxcl1, Cxcl2, Cxcl5, Ccl17, or Cxcr6, etc.) were upregulated by BG pretreatment leading to enrichment of this pathway in our analysis. Finally, osteoclasts differentiation pathway appeared significantly and 
TABLE 1 | Top-10 list of the most differentially expressed genes after BG75 treatment upon lipopolysaccharide (LPS) exposure.

\begin{tabular}{|c|c|c|c|c|c|c|c|c|}
\hline \multicolumn{3}{|c|}{ (A) $\uparrow$ Up-regulated, Pretreated versus mock (fold change) } & \multicolumn{3}{|l|}{$4 \mathrm{~h}$ LPS } & \multicolumn{3}{|c|}{$8 \mathrm{~h}$ LPS } \\
\hline Rank & Gene & Gene title & $\begin{array}{l}\text { Saccharomyces cerevisiae } \\
\text { cell wall (ScCW) }\end{array}$ & BG65 & BG75 & $\mathrm{ScCW}$ & BG65 & BG75 \\
\hline 1 & Csf2 & Colony stimulating factor 2 (granulocyte-macrophage) & 1.8 & 20.3 & 14.0 & 4.2 & 64.9 & 43.1 \\
\hline 2 & Fhl2 & Four and a half LIM domains 2 & 2.4 & 43.3 & 31.1 & 1.7 & 41.0 & 35.7 \\
\hline 3 & Hbegf & Heparin-binding EGF-like growth factor & 2.8 & 11.3 & 8.3 & 6.0 & 46.0 & 32.6 \\
\hline 4 & Inhba & Inhibin beta-A & 16.3 & 20.1 & 15.3 & 20.9 & 41.0 & 29.9 \\
\hline 5 & Car2 & Carbonic anhydrase ॥ & 10.9 & 29.2 & 19.6 & 9.8 & 36.9 & 27.2 \\
\hline 6 & Dok7 & Docking protein 7 & 9.4 & 19.6 & 13.1 & 11.8 & 34.0 & 22.9 \\
\hline 7 & Csf3 & Colony stimulating factor 3 (granulocyte) & 32.1 & 11.4 & 12.7 & 15.2 & 21.2 & 19.2 \\
\hline 8 & Cish & Cytokine inducible $\mathrm{SH} 2$-containing protein & -2.9 & 3.0 & 2.1 & 1.5 & 19.8 & 13.0 \\
\hline 9 & F3 & Coagulation factor III & 1.8 & 5.6 & 4.8 & 2.1 & 13.1 & 11.4 \\
\hline 10 & Vasn & Vasorin & 1.6 & 4.5 & 3.3 & 3.2 & 13.3 & 10.8 \\
\hline \multicolumn{3}{|c|}{$\begin{array}{l}\text { (B) } \uparrow \text { Up-regulated, } \beta \text {-glucan (BG)- versus Saccharomyces cerevisiae } \\
\text { cell wall-pretreated (fold change) }\end{array}$} & & \multicolumn{2}{|c|}{$4 \mathrm{~h}$ LPS } & & \multicolumn{2}{|c|}{8 h LPS } \\
\hline Rank & Gene & Gene title & & BG65 & BG75 & & BG65 & BG75 \\
\hline 1 & Fhl2 & Four and a half LIM domains 2 & & 18.0 & 13.0 & & 24.1 & 20.9 \\
\hline 2 & Csf2 & Colony stimulating factor 2 (granulocyte-macrophage) & & 11.3 & 7.8 & & 15.5 & 10.3 \\
\hline 3 & Cish & Cytokine inducible $\mathrm{SH}$ 2-containing protein & & 8.7 & 5.9 & & 13.1 & 8.6 \\
\hline 4 & Lrrc32 & Leucine rich repeat containing 32 & & 8.2 & 6.0 & & 11.0 & 8.0 \\
\hline 5 & Cc/17 & C-C motif chemokine ligand 17 & & 6.4 & 4.3 & & 10.3 & 6.6 \\
\hline 6 & F3 & Coagulation factor III (thromboplastin, tissue factor) & & 3.2 & 2.7 & & 6.4 & 5.5 \\
\hline 7 & Hbegf & Heparin-binding EGF-like growth factor & & 4.0 & 2.9 & & 7.6 & 5.4 \\
\hline 8 & Tnfsf18 & Tumor necrosis factor superfamily member 18 & & 1.7 & 1.8 & & 4.9 & 4.8 \\
\hline 9 & Spry1 & Sprouty RTK signaling antagonist 1 & & 1.8 & 1.5 & & 5.1 & 4.7 \\
\hline 10 & Egr2 & Early growth response 2 & & 4.3 & 3.4 & & 5.4 & 4.7 \\
\hline
\end{tabular}

specifically associated with BG condition as a result of the overexpression of Fhl2.

\section{GM-CSF Enhances BG Signaling but Is Not Primarily Involved in the Improvement of BG-Primed Macrophage Response to a Secondary TLR Stimulus}

We first confirmed by RT-qPCR that, as observed in the microarray analysis, Csf2 expression was dramatically upregulated in macrophages pretreated with BG and further stimulated by LPS (Figure 4A). This induction appeared highly associated with BG signaling in macrophages, as a huge difference of expression could be observed with BG-enriched preparations and ScCW or mock. At the protein levels, the quantification of GM-CSF (Csf2 expression product) by ELISA confirmed data from the gene expression analysis and showed an increased production of GM-CSF that correlated with the degree of BG enrichment after a secondary LPS stimulation (Figure 4B). Taken together, these data strongly suggested that GM-CSF production by macrophages was highly associated with BG recognition by macrophages. The use of Dectin-1-deficient macrophages in this model of pretreatment/ stimulation induced a strong inhibition of GM-CSF secretion and confirmed that Dectin-1 signaling is essential in this process (Figure 4B). In a previously published study, we demonstrated that Csf2 expression was readily induced in macrophages stimulated by BG only (23). We also reported that macrophages stimulation with $\mathrm{BG}$ resulted in a very marginal secretion of inflammatory cytokines. It has been previously demonstrated that Curd, a linear $\beta(1,3)$-glucan from $A$. faecalis, a gram negative bacterium, could synergize with GM-CSF and confer a strong inflammatory signature to dendritic cells (14). Thus, we examined the influence of recombinant GM-CSF on macrophage activation by BG. As previously observed, BG stimulation on its own induced a very low cytokine production $(<50 \mathrm{pg} / \mathrm{mL})$ by macrophages cultured in the absence of growth factors (Figure 4C). However, preincubating macrophages with $\mathrm{rGM}-\mathrm{CSF}(5 \mathrm{ng} / \mathrm{mL})$ for $2 \mathrm{~h}$ before BG stimulation dramatically increased the resulting levels of cytokine secretion. This effect appeared highly associated with rGM-CSF as pre-incubation with rM-CSF (Csf1 expression product), another major hematopoietic factor influencing macrophages growth, differentiation, and phenotype, did not allow increase of cytokine secretion levels. Using flow cytometry, we confirmed that, as previously described (15), rGM-CSF significantly upregulated the expression of Dectin-1 at the macrophage cell surface (Figure 4D). This effect was not reproduced by pre-incubating cells with rM-CSF. Furthermore, rGM-CSF had no effect on the expression of CR3 (CD11b), another BG receptor. These results suggested that GM-CSF could significantly amplify BG signaling by increasing Dectin-1 expression and consequently be strongly involved in the improved response of BG-primed macrophages to secondary TLR stimuli. And, indeed, pre-incubation of macrophages with rGM-CSF ( $5 \mathrm{ng}$ / $\mathrm{mL}$ ) significantly improved this priming and resulted in levels of TNF $\alpha$ secretion higher than the secretion by macrophages preincubated with $\mathrm{rM}$-CSF or cultured in the absence of stimulating factors (Figure 4E). Of note, rGM-CSF alone induced a moderate increase of cytokine production upon LPS secondary stimulation. 

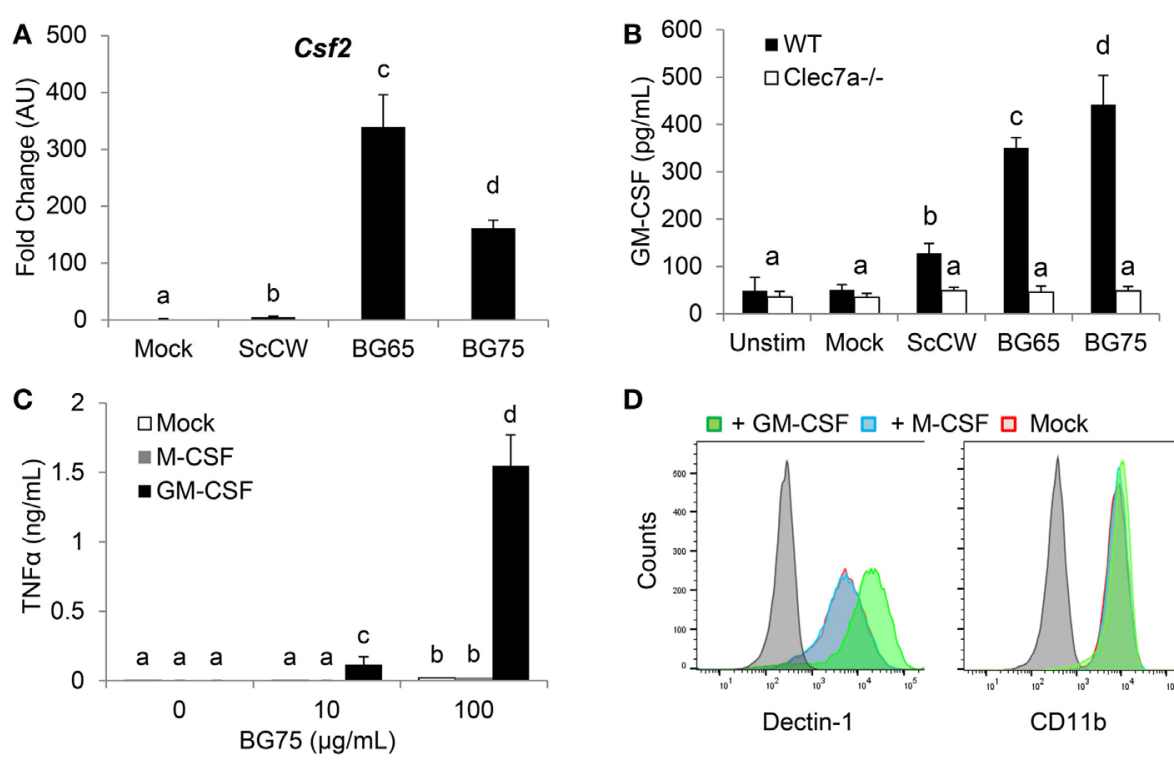

D
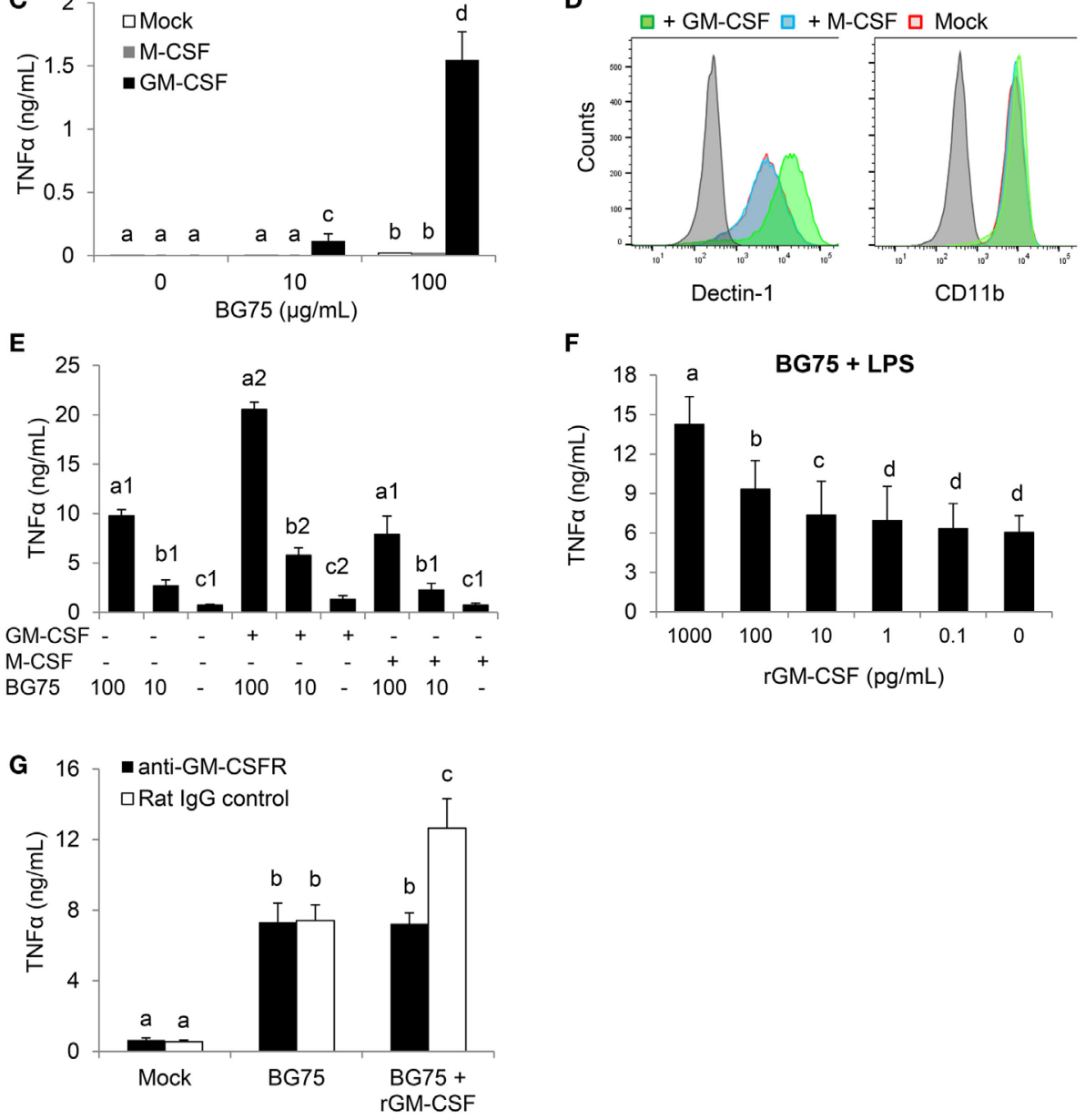

FIGURE 4 | Csf2 upregulation induced by BG-enriched compounds treatment and lipopolysaccharide (LPS) exposure is mainly Dectin-1-dependent. Wild-type or Clec7a-/- bone marrow-derived macrophages (BMDM) were stimulated with $100 \mu \mathrm{g} / \mathrm{mL}$ of the various BG-containing compounds for $8 \mathrm{~h}$. After incubation, cell culture supernatants were removed and $100 \mathrm{ng} / \mathrm{mL}$ of ultraPure LPS or medium was added in each well for $8 \mathrm{~h}$ (A) or $48 \mathrm{~h}$ (B). (A) Supernatants were discarded and BMDM were lysed in RLT lysis buffer. Total RNA was extracted as described before and retro-transcribed. Csf2 expression was determined by quantitative PCR after normalization with three housekeeping genes (Sdha, Rp/9, and Hprt1). Fold change (FC) data are expressed as the mean \pm SD as compared to the mock condition in three independent experiments. Mean values not sharing the same letter are significantly different according to the Student's $t$-test ( $p<0.05)$. (B) After incubation, cell culture supernatants were harvested and stored at $-20^{\circ} \mathrm{C}$. GM-CSF was measured by ELISA. (C-E) WT BMDM were pre-incubated $2 \mathrm{~h}$ with rGM-CSF $(5 \mathrm{ng} / \mathrm{mL})$ or $\mathrm{rM}-\mathrm{CSF}(5 \mathrm{ng} / \mathrm{mL})$ or medium. (C) Cells were further stimulated with $100 \mu \mathrm{g} / \mathrm{mL}$ or $10 \mu \mathrm{g} / \mathrm{mL}$ of BG75 for $8 \mathrm{~h}$. Cell culture supernatants were then removed and TNF $\alpha$ was quantified by ELISA. (D) After incubation, cells were harvested to assess surface expression of Dectin-1 and CD11b by flow cytometry. Expression data of Dectin-1 or CD11b are presented as overlaid histograms for each condition. (E) After pre-incubation with rGM-CSF, rM-CSF, or medium, BMDM were treated with 100 or $10 \mu \mathrm{g} / \mathrm{mL}$ of BG75 for $8 \mathrm{~h}$ before further stimulation with $100 \mathrm{ng} / \mathrm{mL}$ of ultraPure LPS or medium for $16 \mathrm{~h}$. Supernatants were collected and TNF $\alpha$ was measured by ELISA. (F) BMDM were pre-incubated for $2 \mathrm{~h}$ with 10 -fold serial dilutions of rGM-CSF from 0.1 to $1000 \mathrm{pg} / \mathrm{mL}$, before assessment as in (E). (G) In this experiment, BMDM were first incubated with an anti-GM-CSFR monoclonal antibody or its isotype control for 2 h. rGM-CSF (100 pg/mL) was added to cells for $2 \mathrm{~h}$ as a positive control for neutralization. Cells were then stimulated as in (E). Data are expressed as the mean \pm SD from two independent experiments performed in triplicate. Mean values not sharing the same letter are significantly different according to the Student's $t$-test $(p<0.05)$. 
At this step, we could not exclude an endogenous production of GM-CSF during the priming step of macrophages with BG. In a previous study, we showed that macrophage stimulation with BG led to the detection of low levels of GM-CSF secretion (from 1 to $5 \mathrm{pg} / \mathrm{mL}$ ) (23). Thus, we evaluated the effect of rGM-CSF in a dose-dependent manner using our stimulation model and observed that $10 \mathrm{pg} / \mathrm{mL}$ of rGM-CSF were sufficient to improve the priming of macrophages by BG (Figure $4 F$ ). As this dose was not very far from the endogenous levels of production previously measured in BG-treated macrophages, we blocked the GM-CSF activity by using a GM-CSFR blocking antibody. For these experiments, we used rGM-CSF $(100 \mathrm{pg} / \mathrm{mL})$ to validate blocking conditions. As expected, in the absence of blocking antibody, the pretreatment of macrophages with BG enhanced the response to LPS stimulation and addition of rGM-CSF significantly improved the priming of macrophages by BG (Figure 4G). The addition of anti-GM-CSFR completely abolished this gain of response and confirmed that our experimental conditions allowed blocking the activity of at least $100 \mathrm{pg} / \mathrm{mL}$ of GM-CSF. However, the intrinsic ability of BG to prime macrophages response was not affected by the addition of anti-GM-CSFR antibody. This, finally, demonstrated that GM-CSF could improve macrophages priming by BG but was not primarily involved in this mechanism.

\section{Specific Induction of FHL2 by BG-Enriched Pretreatment Is Dectin-1-Dependent}

Significant Fhl2 upregulation in BG-enriched conditions upon a secondary LPS stimulation was confirmed by qPCR (Figure 5A). As Fhl2 expression seems to be highly correlated with the degree of purity of BG in the preparations we used, we next investigated the influence of Dectin-1 on Fhl2 transcription following incubation with BG compounds. WT and Clec $7 a^{-1-}$ BMDM from $\mathrm{C} 57 \mathrm{Bl} / 6$ were incubated $8 \mathrm{~h}$ with BG65/75 and ScCW to examine Fhl2 expression. In WT or Clec $7 a^{-/-}$cells, the gene was basically poorly expressed and even following treatment with ScCW (Figure 5B). However, induction of Fhl2 was triggered by BG65 or BG75 pretreatments (around 5-fold upregulations) in WT cells. Interestingly, Dectin-1-deficiency entailed a severe loss of Fhl2 induction following BG65 treatment and almost abolished it after BG75 incubation. Western Blotting on BMDM lysates confirmed that FHL2 protein was more abundant after pretreatment with BG65 and BG75 (at least 2-fold more as compared to mock) than with ScCW following a secondary LPS stimulation and was poorly detectable in mock condition, with or without LPS stimulation (Figure 5C). Therefore, BG-enriched compounds induce Fhl2 expression, essentially via the Dectin-1 pathway.

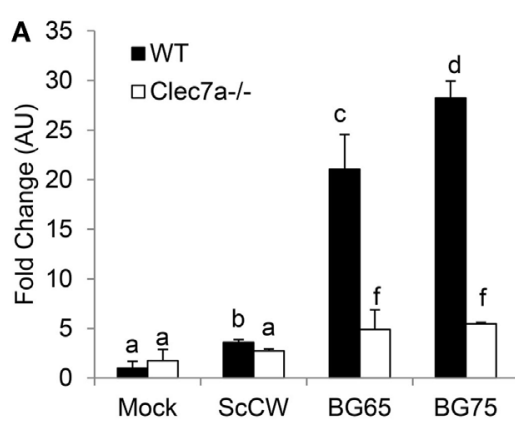

C
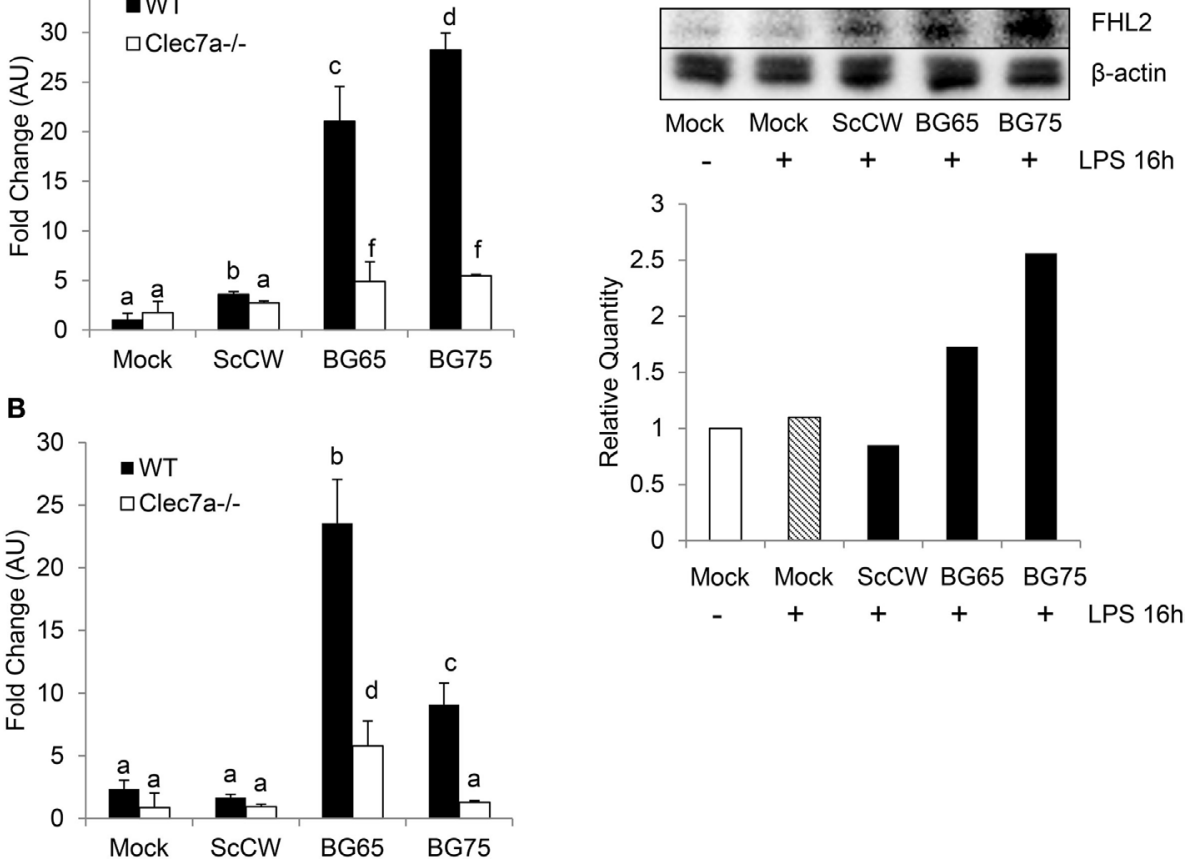

FIGURE 5 | Fh/2 upregulation induced by BG-enriched compounds is under the control of Dectin-1. (A) Wild-type WT or Clec7a $a^{-/-}$bone marrow-derived macrophages (BMDM) were pre-treated as described in Figure 4A. Fhl2 expression was determined by RT-qPCR as described for Csf2. (B) WT or Clec7a ${ }^{-/-}$ BMDM were stimulated with BG-containing compounds for $8 \mathrm{~h}$. At the end of the incubation, BMDM were lysed in RLT lysis buffer. After RNA extraction, cDNA synthesis and RT-qPCR were performed. Data are expressed as the fold change (FC) related to the mock condition value and are representative of two experiments performed in triplicate. (C) WT BMDM were stimulated following the same protocol as in (A). After incubation, BMDM were lysed in RIPA buffer supplemented with $5 \mathrm{mM}$ EDTA and protease inhibitor (Pierce ${ }^{\mathrm{TM}}$ ). After clarification and protein quantitation, $10 \mathrm{mg}$ of total lysates were separated on a polyacrylamide gel. After transfer, nitrocellulose membrane was subjected to Western blotting with anti-FHL2 (F4B2-B11) and anti- $\beta$-actin (C4) mAbs (Santa Cruz Biotechnologies). Blotting was revealed using chemiluminescence. Results are also presented as the relative quantity of FHL2 protein detected in each condition as compared to the reference corresponding to the unstimulated cells. The data are representative of three independent experiments. 


\section{DISCUSSION}

As previously described, the stimulation with $\mathrm{ScCW}$ or Zym led to a strong inflammatory response by macrophages resulting from a synergy between TLR (mainly TLR2) and Dectin-1associated signaling $(17,20,21,32)$. By contrast, and as observed in our former study (23), BG-enriched parietal fractions failed to do so. And yet, the experiments presented here suggest that BG exposure profoundly imprints macrophage, phenotype, and functions. Indeed, we demonstrated that, when pretreated with BG-enriched preparations (BG65, BG75, or WGPd), TEPM or BMDM showed an exacerbated cytokine production in response to a secondary TLR-associated stimulus. This priming effect could be revealed through various secondary stimulations, including TLR2 or TLR4 ligands but also live S. aureus or E. coli. However, whether other ligands or pathogens have the same potential should be further tested.

The pretreatment with soluble BG (WGPs) did not improve macrophage response to LPS stimulation, suggesting that Dectin-1 clustering (33) by particulate BG and subsequent downstream signaling events are prerequisites for macrophage priming. The significant inhibition of priming observed in Dectin-1-deficient macrophages was consistent with this hypothesis. However, this inhibition was only partial and raised the question about the possible involvement of other BG receptors, at least in this experimental model.

Interestingly, the pretreatment with crude ScCW or Zym failed to prime macrophages although both of these yeast-derived preparations do contain BG (15 and $50 \%$, respectively) $(23,34$, 35). In a previous study, using TLR pathway reporter cell lines HEK293, we showed that BG enrichment process from ScCW to BG65 and BG75 removed the majority of TLR agonists including mannans (23). Taken together, these observations suggest that the simultaneous targeting of multiple PRRs, leading to a strong inflammatory response of macrophages, prevents the BG-induced priming.

Such a priming effect of BG was previously observed with the pretreatment of human PBMC with the pathogenic yeast $C$. albicans that results in an enhanced response to TLR-associated secondary stimulus (36). The engineering of $C$. albicans strains demonstrated that BG were central in this effect (36). Similarly, pretreating human monocytes with whole $C$. albicans or purified BG not only led to an enhanced cytokine response but also modified the cell shape, granulosity, and expression of surface markers. This "immune training" was observable in short term (24 h) (36) or long-term conditions (6 days) (37). Here, we unambiguously demonstrated that BG could train fully differentiated mouse macrophages in a short-term model. We also evaluated this training for longer resting periods between pretreatment and LPS re-stimulation. For up to 6 days, we observed increased cytokine production by BG-pretreated cells compared to non-pretreated cells (data not shown). However, these experiments were done in the absence of exogenous M-CSF. Under these conditions, non-pretreated macrophages started to present evident signs of cell suffering after 4 days of culture unlike BG-pretreated macrophages that appeared unaffected by growth factor deprivation. At days 5 and 6, cell numbers were clearly decreased in control wells creating an obvious bias in the measurement of cytokine production after LPS re-stimulation. Consequently, we decided to present data up to 3 days after pretreatment, as we did not observe differences in cell numbers that could explain a 5 -fold increase in cytokine levels.

Taken together, these results fully demonstrate that exposure to fungal BGs profoundly modifies monocyte/macrophage physiology, and functions. Through a microarray analysis, we showed that $\mathrm{BG}$ pretreatment induced a specific set of genes in mouse macrophages. This was highlighted by comparing BG-pretreated cells versus non-pretreated cells or cells pretreated with $\mathrm{ScCW}$ that was shown unable to perform training of macrophages. By doing so, we identified molecular pathways preferentially triggered by BG. These pathways were highly related to PI3K cascade upstream of AKT. Consistently, we also found that GPCR signaling, known to activate PI3K cascade, was involved in BG-induced priming of macrophages. These findings were in agreement with previous studies, indicating that BGs induce a metabolic shift toward aerobic glycolysis mediated by an AKT-mTOR-HIF1 $\alpha$ pathway in human monocytes $(28,37)$. Furthermore, BG-trained monocytes revealed higher intracellular ratio of nicotinamide adenine dinucleotide $\left(\mathrm{NAD}^{+}\right)$to its reduced form $(\mathrm{NADH})(28)$. We showed higher fluorescence of resofurin in BG75-treated BMDM using a Biotool Vita-Blue Cell Viability reagent. This assay is based on a redox reaction that transforms weakly fluorescent resazurin to highly fluorescent resofurin by oxidation of $\mathrm{NADH}$ in $\mathrm{NAD}^{+}$in metabolically active cells, meaning that BG-treated $\mathrm{BMDM}$ displayed higher $\mathrm{NAD}^{+} / \mathrm{NADH}$ ratio, in line with results reported by Cheng et al.

By contrast, ScCW pretreatment mainly induced TLRassociated pathways signaling that is in line with our previous observations, showing a robust inflammatory response of macrophages through NFKB activation mediated by MyD88dependent pathways after exposure with crude yeast CW or Zym (23). The leukotriene pathway was also triggered by ScCW pretreatment which is consistent with findings concerning Zym activity on human monocytes (38).

The microarray analysis consistently identified Csf2 (that encodes for GM-CSF), the keystone of the gene network, and Fhl2 as the two main upregulated genes by BG65 and BG75 priming conditions. IPA analysis revealed their enrichment for inflammatory response, proliferation and differentiation of bone marrow progenitors, migration and binding of cells, in antigen presentation and cell survival, immune cell trafficking, and development of hematological system. These two genes further targeted pathways highlighting the crucial role of cytokines as mediators of the communication between innate and adaptive responses.

GM-CSF is a highly pleiotropic cytokine and a growth factor involved in the differentiation of hematopoietic progenitors from bone marrow but GM-CSF is also recognized as a key mediator during inflammation (39-41).

In this study, we demonstrated that Csf2 expression and GM-CSF production were highly specific of BG pretreatment as $\mathrm{ScCW}$ pretreatment failed to do so. Moreover, this dramatic enhancement was totally abrogated in Dectin-1-deficient macrophages, confirming the strong association between Dectin-1 
and GM-CSF production. In agreement with this result, it was demonstrated that pre-incubating dendritic cells with GM-CSF substantially enhances the cytokine secretion upon Curd, a linear BG from A. faecalis stimulation (14). By using flow cytometry, we showed that GM-CSF treatment increased Dectin-1 expression on BMDM as previously observed with dendritic cells or with resident and thioglycollate-elicited macrophages treated with GM-CSF or IL- 4 or a combination of both cytokines $(12,14,15)$. It was, thus, suggested that such an upregulation of Dectin-1 expression consequently to GM-CSF allows Dectin-1-mediated TNF $\alpha$ induction (12). In line with this, GM-CSF was shown to be required to trigger a robust production of TNF $\alpha$, IL- 6 , and IL- $1 \beta$ in Curd-stimulated dendritic cells (14).

In a previous study, we evidenced a late Dectin-1-dependent overexpression of Csf2 following stimulation with BG65 or BG75 but unexpectedly, we found very low amounts $(<5 \mathrm{pg} / \mathrm{mL})$ of GM-CSF in culture supernatants even after $24 \mathrm{~h}$ of incubation (23). By contrast, the stimulation of peritoneal macrophages with soluble BG from Grifola frondosa mushroom results in a significant expression of Csf2 with subsequent production of GM-CSF (100 pg/mL) after $6 \mathrm{~h}$ of incubation (12). However and again in contrast with our results, the induction of GM-CSF production by soluble BG appeared to be Dectin-1-independent confirming that particulate and soluble BG do not trigger similar pathways. In agreement with this, we showed here that, compared to $S c$ particulate BG, soluble BGs (WGPs) were unable to induce macrophages priming.

Our data seem to target GM-CSF as a pivotal actor of the BG-induced priming of macrophages. Consistently with this hypothesis, GM-CSF-treated macrophages/monocytes exposed to TLR2 or TLR4 ligands were shown to produce significantly more IL-1 $\beta$, IL-6, and TNF $\alpha$ (30, 40-42). Furthermore, GM-CSF was also able to prevent endotoxin tolerance in macrophages by restoring TNF $\alpha$ production on LPS-tolerized human monocytes (43).

Similarly, it was very recently shown that GM-CSF, and IL-3, on its own, was sufficient to train human monocytes in a p38- and SIRT2-dependent manner (30). In this study, we also observed that GM-CSF pretreatment of mouse macrophages induced a moderate but significant increase of cytokine secretion upon LPS re-stimulation. Yet, this training effect remained much lower than the one mediated by BG or GM-CSF plus BG.

As GM-CSF appears to be strongly related to the priming of macrophages by particulate BG, we further investigated the influence of GM-CSF on BG-induced TNF $\alpha$ production.

Using decreasing concentrations of rGM-CSF during BG pretreatment, we showed that $10 \mathrm{pg} / \mathrm{mL}$ were enough to improve the priming of macrophages. Taken together with our previous observations, this result suggests that the endogenous production of GM-CSF induced by BG along the pretreatment step could be responsible for macrophage training. To rule out this hypothesis, we inhibited GM-CSF-associated signaling in macrophages by using a GM-CSFR blocking antibody. The amount of blocking antibody used was sufficient to completely inhibit the activity of $100 \mathrm{pg} / \mathrm{mL}$ rGM-CSF, a far greater concentration than the one supposed to be produced endogenously following BG pretreatment. Under these conditions, we showed that blockade of GM-CSF pathway did not affect the levels of training induced by BG, highlighting that endogenous GM-CSF is not required for the BG-induced training of macrophages, which clearly argues against results from previous studies in favor of a strong reduction of BG-induced TNF $\alpha$ in macrophages neutralized with anti-GM-CSF antibodies $(12,44)$.

Taken together, our results demonstrate that GM-CSF, which is endowed with low immune training properties on its own, is not intrinsically involved in the BG-induced training of macrophages although it can substantially improve it. However, we cannot exclude a contribution of GM-CSF in the long-term training model, as it favors cell survival and adherence (39-41, 45). This later hypothesis should be accurately investigated.

Intriguingly, we identified Fhl2 (four-and-a-half LIM-only protein 2) as the second most upregulated gene in macrophages pretreated with BG and further stimulated with LPS. We demonstrated that Fhl2 expression was specifically induced by BG in a Dectin-1-dependent manner. At the protein level, we showed that production of FHL2 was significantly increased after BG pretreatment and was not influenced by the secondary LPS stimulation. Here, we revealed for the first time the involvement of Fhl2 in Dectin-1-mediated pathway. Again, ScCW was not able to modulate FHL2 expression and production, confirming the predominant role of Dectin-1- as compared to TLR-associated pathways.

Fhl2 is expressed in a cell-and tissue-specific manner and molecular mechanisms by which this protein exerts its roles remain incompletely understood, especially in cells where its expression is limited or absent. Moreover, according to its cytoplasmic or nuclear localization within the cell, FHL2 seems to have highly variable molecular partners as reviewed in Ref. (46) and to play important role as mediator in many signaling pathways, including NFKB signaling pathways $(47,48)$ or TGF- $\beta$ signaling $(49,50)$.

Interestingly, FHL2 was reported to interact with $\mathrm{NF \kappa B}$ but in a cell type-dependent manner. Indeed, FHL2 has been shown to inhibit NFkB activity during osteoclastogenesis by displacing TRAF6 from RANK (51). By contrast, FHL2 was shown to mediate IL-6 production through NFkB and p38 MAPK signaling pathway in muscle cells (48). Similarly, FHL2-deficiency in macrophages significantly reduced TNF $\alpha$ and IL- 6 production following LPS exposure, suggesting that FHL2 acts as a positive regulator of NFKB through TRAF6 in liver macrophages (47) but also in FHL2-transfected HEK cells (52). Although our study does not bring definitive proofs of FHL2 involvement in shortterm training of macrophages, its $\mathrm{NF \kappa B}$ activating capacity is not consistent with the high levels of cytokine secretion recorded by BG-primed macrophages upon a secondary TLR-associated stimulation. Indeed, $\mathrm{NF \kappa B}$ activity recorded in BG-trained BMDM was similar in ScCW-incubated cells, meaning that BG immune training is poorly correlated with NFkB-related signaling. Consequently, it remains highly plausible that FHL2 interacts with other nuclear transcription factors or cell signaling molecules.

However, there is no evidence that FHL2 activity directly result from Dectin-1 triggering and downstream signaling. 
Indeed, we observed that at least $8 \mathrm{~h}$ of BG pretreatment were needed to induce macrophage priming and that $16 \mathrm{~h}$ of incubation with LPS were required to reveal macrophage training. These incubation times are sufficient to allow de novo synthesis of molecules that could link Dectin-1 and FHL2 activity. Undeniably, further investigations will be needed to decipher FHL2 regulation by Dectin-1 pathway and the associated molecular mechanisms.

Altogether, we established for the first time a short-term model of trained immunity with mouse macrophages using BG from $S$. cerevisiae and evidenced GM-CSF and FHL2 as potential co-actors of this priming effect. Considering the availability of industrial byproducts of $S$. cerevisiae, reprogramming monocytes/macrophages becomes possible using BG from this source to improve their response against invading pathogens.

\section{ETHICS STATEMENT}

WT C57Bl/6 mice were purchased from Janvier Labs (St Berthevin, France) and Clec7 $\mathrm{a}^{-/-}$mice (5) were originally provided by Pr. Gordon Brown (University of Aberdeen, Scotland) and were bred in-house. Eight- to 12 -week-old C57Bl/6 Clec7a ${ }^{-/-}$ mice and their strain-matched WT controls from both sexes were housed under pathogen-free conditions in an accredited research animal facility of the National Veterinary College (UMR IHAP, Toulouse, France). This study was carried out in strict accordance with the Federation of European Laboratory Animal Science Association guidelines (FELASA). Experiments were performed by FELASA accredited investigators (no. 311155580) and approved by the local ethics committee, "Science et Santé Animale" (SSA). All efforts were made to minimize animal pain and distress.

\section{REFERENCES}

1. Taylor PR, Martinez-Pomares L, Stacey M, Lin H-H, Brown GD, Gordon S. Macrophage receptors and immune recognition. Annu Rev Immunol (2005) 23:901-44. doi:10.1146/annurev.immunol.23.021704.115816

2. Creagh EM, O'Neill LAJ. TLRs, NLRs and RLRs: a trinity of pathogen sensors that co-operate in innate immunity. Trends Immunol (2006) 27:352-7. doi:10.1016/j.it.2006.06.003

3. Goodridge HS, Underhill DM. Fungal recognition by TLR2 and dectin-1. Handb Exp Pharmacol (2008) 183:87-109. doi:10.1007/978-3-54072167-3_5

4. LeibundGut-Landmann S, Groß O, Robinson MJ, Osorio F, Slack EC, Tsoni SV, et al. Syk- and CARD9-dependent coupling of innate immunity to the induction of T helper cells that produce interleukin 17. Nat Immunol (2007) 8:630-8. doi:10.1038/ni1460

5. Taylor PR, Tsoni SV, Willment JA, Dennehy KM, Rosas M, Findon H, et al. Dectin- 1 is required for $\beta$-glucan recognition and control of fungal infection. Nat Immunol (2007) 8:31-8. doi:10.1038/ni1408

6. Netea MG, Gow NA, Munro CA, Bates S, Collins C, Ferwerda G, et al. Immune sensing of Candida albicans requires cooperative recognition of mannans and glucans by lectin and toll-like receptors. J Clin Invest (2006) 116:1642-50. doi:10.1172/JCI27114

7. Underhill DM, Rossnagle E, Lowell CA, Simmons RM. Dectin-1 activates Syk tyrosine kinase in a dynamic subset of macrophages for reactive oxygen production. Blood (2005) 106:2543-50. doi:10.1182/blood-2005-03-1239

8. Goodridge HS, Shimada T, Wolf AJ, Hsu Y-MS, Becker CA, Lin X, et al. Differential use of CARD9 by dectin-1 in macrophages and dendritic cells. J Immunol (2009) 182:1146-54. doi:10.4049/jimmunol.182.2.1146

\section{AUTHOR CONTRIBUTIONS}

Participated in research design: SW, GF, and GT; conducted experiments: SW, GT, and MF; performed data analysis: SW, GF, and GT; wrote or contributed to the writing of the manuscript: SW, GF, and GT.

\section{ACKNOWLEDGMENTS}

The authors would like to thank Dr. A. Roulet from the GeTPlaGe platform (INRA, Toulouse) for analyzing gene expression using Biomark HD system (Fluidigm). We also thank Dr. Y. Lippi and C. Naylies from the GeT-TRiX platform (Toxalim, INRA, Toulouse) for helping in the microarray analysis. Finally, we thank Pr. GD. Brown (University of Aberdeen) for supplying us with $\mathrm{C} 57 \mathrm{Bl} / 6 \mathrm{Clec} \mathrm{a} \mathrm{a}^{-/-}$mice. This manuscript includes for part Dr. Walachowski PhD thesis dataset (53).

\section{FUNDING}

This work was partly financed by Phileo-Lesaffre Animal Care. This work has received support from an "Investissements d'avenir" grant managed by Agence Nationale de la Recherche under the reference ANR-11-EQPX-0003 and from a joint call between "Institut Carnot en Santé Animale" and "Institut Carnot Pasteur Maladies Infectieuses" under the reference Glucastimmune.

\section{SUPPLEMENTARY MATERIAL}

The Supplementary Material for this article can be found online at http://journal.frontiersin.org/article/10.3389/fimmu.2017.01089/ full\#supplementary-material.

9. Brown GD, Taylor PR, Reid DM, Willment JA, Williams DL, MartinezPomares L, et al. Dectin-1 is a major $\beta$-glucan receptor on macrophages. J Exp Med (2002) 196:407-12. doi:10.1084/jem.20020470

10. Rogers NC, Slack EC, Edwards AD, Nolte MA, Schulz O, Schweighoffer $\mathrm{E}$, et al. Syk-dependent cytokine induction by dectin-1 reveals a novel pattern recognition pathway for C type lectins. Immunity (2005) 22:507-17. doi:10.1016/j.immuni.2005.03.004

11. Gross O, Gewies A, Finger K, Schäfer M, Sparwasser T, Peschel C, et al. Card9 controls a non-TLR signalling pathway for innate anti-fungal immunity. Nature (2006) 442:651-6. doi:10.1038/nature04926

12. Masuda Y, Togo T, Mizuno S, Konishi M, Nanba H. Soluble $\beta$-glucan from Grifola frondosa induces proliferation and dectin-1/Syk signaling in resident macrophages via the GM-CSF autocrine pathway. JLeukoc Biol (2012) 91:547-56. doi:10.1189/jlb.0711386

13. Harada T, Ohno N. Contribution of dectin-1 and granulocyte macrophagecolony stimulating factor (GM-CSF) to immunomodulating actions of $\beta$-glucan. Int Immunopharmacol (2008) 8:556-66. doi:10.1016/j.intimp.2007.12.011

14. Min L, Isa SABM, Fam WN, Sze SK, Beretta O, Mortellaro A, et al. Synergism between curdlan and GM-CSF confers a strong inflammatory signature to dendritic cells. J Immunol (2012) 188:1789-98. doi:10.4049/jimmunol.1101755

15. Willment JA, Lin H-H, Reid DM, Taylor PR, Williams DL, Wong SYC, et al. Dectin-1 expression and function are enhanced on alternatively activated and GM-CSF-treated macrophages and are negatively regulated by IL-10, dexamethasone, and lipopolysaccharide. J Immunol (2003) 171:4569-73. doi:10.4049/jimmunol.171.9.4569

16. Saijo S, Fujikado N, Furuta T, Chung S, Kotaki H, Seki K, et al. Dectin-1 is required for host defense against Pneumocystis carinii but not against Candida albicans. Nat Immunol (2007) 8:39-46. doi:10.1038/ni1425 
17. Ferwerda G, Meyer-Wentrup F, Kullberg B-J, Netea MG, Adema GJ. Dectin-1 synergizes with TLR2 and TLR4 for cytokine production in human primary monocytes and macrophages. Cell Microbiol (2008) 10:2058-66. doi:10.1111/j.1462-5822.2008.01188.x

18. Lebron F, Vassallo R, Puri V, Limper AH. Pneumocystis carinii cell wall $\beta$-glucans initiate macrophage inflammatory responses through NF- $\mathrm{\kappa B}$ activation. J Biol Chem (2003) 278:25001-8. doi:10.1074/jbc.M301426200

19. Underhill DM. Collaboration between the innate immune receptors dectin-1, TLRs, and Nods. Immunol Rev (2007) 219:75-87. doi:10.1111/j.1600-065X.2007.00548.x

20. Gantner BN, Simmons RM, Canavera SJ, Akira S, Underhill DM. Collaborative induction of inflammatory responses by dectin-1 and toll-like receptor 2 . J Exp Med (2003) 197:1107-17. doi:10.1084/jem.20021787

21. Dennehy KM, Ferwerda G, Faro-Trindade I, Pyż E, Willment JA, Taylor PR, et al. Syk kinase is required for collaborative cytokine production induced through dectin-1 and toll-like receptors. Eur J Immunol (2008) 38:500-6. doi:10.1002/eji.200737741

22. Yadav M, Schorey JS. The $\beta$-glucan receptor dectin- 1 functions together with TLR2 to mediate macrophage activation by mycobacteria. Blood (2006) 108:3168-75. doi:10.1182/blood-2006-05-024406

23. Walachowski S, Tabouret G, Foucras G. Triggering dectin-1-pathway alone is not sufficient to induce cytokine production by murine macrophages. PLoS One (2016) 11:e0148464. doi:10.1371/journal.pone.0148464

24. Quintin J, Saeed S, Martens JHA, Giamarellos-Bourboulis EJ, Ifrim DC, Logie $\mathrm{C}$, et al. Candida albicans infection affords protection against reinfection via functional reprogramming of monocytes. Cell Host Microbe (2012) 12:223-32. doi:10.1016/j.chom.2012.06.006

25. Bistoni F, Vecchiarelli A, Cenci E, Puccetti P, Marconi P, Cassone A. Evidence for macrophage-mediated protection against lethal Candida albicans infection. Infect Immun (1986) 51:668-74.

26. Netea MG, Quintin J, van der Meer JWM. Trained immunity: a memory for innate host defense. Cell Host Microbe (2011) 9:355-61. doi:10.1016/j. chom.2011.04.006

27. van der Meer JWM, Joosten LAB, Riksen N, Netea MG. Trained immunity: a smart way to enhance innate immune defence. Mol Immunol (2015) 68:40-4. doi:10.1016/j.molimm.2015.06.019

28. Cheng S-C, Quintin J, Cramer RA, Shepardson KM, Saeed S, Kumar V, et al. mTOR- and HIF- $1 \alpha$-mediated aerobic glycolysis as metabolic basis for trained immunity. Science (2014) 345:1250684. doi:10.1126/science.1250684

29. Saeed S, Quintin J, Kerstens HHD, Rao NA, Aghajanirefah A, Matarese F, et al. Epigenetic programming of monocyte-to-macrophage differentiation and trained innate immunity. Science (2014) 345:1251086. doi:10.1126/ science. 1251086

30. Borriello F, Iannone R, Di Somma S, Loffredo S, Scamardella E, Galdiero MR, et al. GM-CSF and IL-3 modulate human monocyte TNF- $\alpha$ production and renewal in in vitro models of trained immunity. Front Immunol (2017) 7:680. doi:10.3389/fimmu.2016.00680

31. Accarias S, Lugo-Villarino G, Foucras G, Neyrolles O, Boullier S, Tabouret G. Pyroptosis of resident macrophages differentially orchestrates inflammatory responses to Staphylococcus aureus in resistant and susceptible mice. Eur J Immunol (2015) 45:794-806. doi:10.1002/eji.201445098

32. Brown GD, Herre J, Williams DL, Willment JA, Marshall ASJ, Gordon S. Dectin-1 mediates the biological effects of $\beta$-glucans. J Exp Med (2003) 197:1119-24. doi:10.1084/jem.20021890

33. Goodridge HS, Reyes CN, Becker CA, Katsumoto TR, Ma J, Wolf AJ, et al. Activation of the innate immune receptor dectin-1 upon formation of a "phagocytic synapse". Nature (2011) 472:471-5. doi:10.1038/nature10071

34. Carlo FJD, Fiore JV. On the composition of zymosan. Science (1958) 127:756-7. doi:10.1126/science.127.3301.756-a

35. Riggi SJ, Di Luzio NR. Identification of a reticuloendothelial stimulating agent in zymosan. Am J Physiol (1961) 200:297-300.

36. Ifrim DC, Joosten LAB, Kullberg B-J, Jacobs L, Jansen T, Williams DL, et al. Candida albicans primes TLR cytokine responses through a dectin-1/ Raf-1-mediated pathway. JImmunol (2013) 190:4129-35. doi:10.4049/ jimmunol.1202611

37. Ifrim DC, Quintin J, Joosten LAB, Jacobs C, Jansen T, Jacobs L, et al. Trained immunity or tolerance: opposing functional programs induced in human monocytes after engagement of various pattern recognition receptors. Clin Vaccine Immunol (2014) 21:534-45. doi:10.1128/CVI.00688-13
38. Czop JK, Austen KF. Generation of leukotrienes by human monocytes upon stimulation of their beta-glucan receptor during phagocytosis. Proc Natl Acad Sci U S A (1985) 82:2751-5. doi:10.1073/pnas.82.9.2751

39. Hamilton JA, Anderson GP. GM-CSF biology. Growth Factors (2004) 22:225-31. doi:10.1080/08977190412331279881

40. Sorgi CA, Rose S, Court N, Carlos D, Paula-Silva FWG, Assis PA, et al. GM-CSF priming drives bone marrow-derived macrophages to a pro-inflammatory pattern and downmodulates PGE2 in response to TLR2 ligands. PLoS One (2012) 7:e40523. doi:10.1371/journal.pone.0040523

41. Däbritz J, Weinhage T, Varga G, Wirth T, Walscheid K, Brockhausen A, et al. Reprogramming of monocytes by GM-CSF contributes to regulatory immune functions during intestinal inflammation. J Immunol (2015) 194:2424-38. doi:10.4049/jimmunol.1401482

42. Rosas M, Liddiard K, Kimberg M, Faro-Trindade I, McDonald JU, Williams $\mathrm{DL}$, et al. The induction of inflammation by dectin-1 in vivo is dependent on myeloid cell programming and the progression of phagocytosis. J Immunol (2008) 181:3549-57. doi:10.4049/jimmunol.181.5.3549

43. Adib-Conquy M, Cavaillon J-M. Gamma interferon and granulocyte/ monocyte colony-stimulating factor prevent endotoxin tolerance in human monocytes by promoting interleukin-1 receptor-associated kinase expression and its association to MyD88 and not by modulating TLR4 expression. J Biol Chem (2002) 277:27927-34. doi:10.1074/jbc.M200705200

44. Harada T, Miura NN, Adachi Y, Nakajima M, Yadomae T, Ohno N. Granulocyte-macrophage colony-stimulating factor (GM-CSF) regulates cytokine induction by $1,3-\beta$-D-glucan SCG in DBA/2 mice in vitro. J Interferon Cytokine Res (2004) 24:478-89. doi:10.1089/1079990041689656

45. Lacey DC, Achuthan A, Fleetwood AJ, Dinh H, Roiniotis J, Scholz GM, et al. Defining GM-CSF- and macrophage-CSF-dependent macrophage responses by in vitro models. J Immunol (2012) 188:5752-65. doi:10.4049/ jimmunol.1103426

46. Johannessen M, Møller S, Hansen T, Moens U, Ghelue MV. The multifunctional roles of the four-and-a-half-LIM only protein FHL2. Cell Mol Life Sci (2006) 63:268-84. doi:10.1007/s00018-005-5438-Z

47. Dahan J, Nouët $Y$, Jouvion G, Levillayer F, Adib-Conquy M, Cassard-Doulcier $\mathrm{A}-\mathrm{M}$, et al. LIM-only protein FHL2 activates NF- $\mathrm{kB}$ signaling in the control of liver regeneration and hepatocarcinogenesis. Mol Cell Biol (2013) 33:3299-308. doi:10.1128/MCB.00105-13

48. Wong C-H, Mak GW-Y, Li M-S, Tsui SK-W. The LIM-only protein FHL2 regulates interleukin-6 expression through p38 MAPK mediated NF- $\mathrm{\kappa B}$ pathway in muscle cells. Cytokine (2012) 59:286-93. doi:10.1016/j.cyto.2012.04.044

49. Ding L, Wang Z, Yan J, Yang X, Liu A, Qiu W, et al. Human four-and-a-half LIM family members suppress tumor cell growth through a TGF- $\beta$-like signaling pathway. J Clin Invest (2009) 119:349-61. doi:10.1172/JCI35930

50. Xia T, Lévy L, Levillayer F, Jia B, Li G, Neuveut C, et al. The four and a half LIM-only protein 2 (FHL2) activates transforming growth factor $\beta$ (TGF- $\beta$ ) signaling by regulating ubiquitination of the E3 ligase Arkadia. J Biol Chem (2013) 288:1785-94. doi:10.1074/jbc.M112.439760

51. Bai S, Kitaura H, Zhao H, Chen J, Müller JM, Schüle R, et al. FHL2 inhibits the activated osteoclast in a TRAF6-dependent manner. J Clin Invest (2005) 115:2742-51. doi:10.1172/JCI24921

52. Stilo R, Leonardi A, Formisano L, Di Jeso B, Vito P, Liguoro D. TUCAN/ CARDINAL and DRAL participate in a common pathway for modulation of NF-kB activation. FEBS Lett (2002) 521:165-9. doi:10.1016/ S0014-5793(02)02869-7

53. Walachowski S. Etude des propriétés immunostimulantes de composés pariétaux de levure sur les macrophages murins et évaluation dans des modèles infectieux. (2016). Available from: https://tel.archives-ouvertes.fr/tel-01477575/ document

Conflict of Interest Statement: The authors declare that the research was conducted in the absence of any commercial or financial relationships that could be construed as a potential conflict of interest.

Copyright $\odot 2017$ Walachowski, Tabouret, Fabre and Foucras. This is an open-access article distributed under the terms of the Creative Commons Attribution License (CC $B Y)$. The use, distribution or reproduction in other forums is permitted, provided the original author(s) or licensor are credited and that the original publication in this journal is cited, in accordance with accepted academic practice. No use, distribution or reproduction is permitted which does not comply with these terms. 